Research Article

\title{
Bearing Seat Vibration Modes Undergoing Unbalanced Excitation of Multirotating Drums
}

\author{
Yu Li, Zhong Tang $\left(\mathbb{D}\right.$, Xinzhong Wang $\mathbb{D}^{D}$, Hao Zhang, and Yaoming Li \\ Key Laboratory of Modern Agricultural Equipment and Technology of Ministry of Education, Jiangsu University, Zhenjiang, \\ Jiangsu 212013, China \\ Correspondence should be addressed to Xinzhong Wang; xzwang@ujs.edu.cn
}

Received 23 August 2021; Accepted 4 December 2021; Published 28 December 2021

Academic Editor: Vasudevan Rajamohan

Copyright (c) $2021 \mathrm{Yu} \mathrm{Li}$ et al. This is an open access article distributed under the Creative Commons Attribution License, which permits unrestricted use, distribution, and reproduction in any medium, provided the original work is properly cited.

Transmission modes of multiple rotating parts on combine harvester are complex and diverse, which resulted in large vibration and poor stability when the entire machine is harvesting. Aiming at the complex vibration problem of the combine harvester threshing system, this paper established the dynamic response model of the multidrum parallel system under different transmission modes and solved the vibration characteristics of the system. An experiment on the axial unbalance response of the parallel drum system under different transmission modes was carried out. The results show that the internal units of the threshing system form a whole through the transmission system, which causes the unbalanced response of the system to be superimposed on parallel threshing drums, thereby increasing the vibration amplitude. In addition, the change of the transmission mode will cause the vibration transmission path in the system to change greatly, and the boundary conditions of the system will be changed at the same time, which will eventually lead to the change of the unbalanced response characteristics.

\section{Introduction}

As a complex agricultural machine, combine harvester can achieve operations such as cutting, threshing, separating, and cleaning crops at one time $[1,2]$. However, combine harvesters generally suffer from severe vibration when working, which seriously affects harvesting efficiency and drivers' physical and mental health $[3,4]$. In combine harvester as a typical rotating machine, there are multiple parallel rotating bodies inside the combine harvester. Threshing drum is the main working part to complete the grain harvested. Some problems such as transmission imbalance, structural degeneration, and component damage will occur after the assembly of the whole machine is completed and after long-term work.

The threshing drum is a typical rotating machine. There are many researches on the basic motion $[5,6]$ and vibration response [7-9] of rotating machines in the engineering field. Establishment of dynamic system equations is the basis for studying the vibration characteristics. Wu et al. [10] used the Newmark method to numerically calculate the vibration of the car under basic motion, and the result showed that the system has a good vibration response. There are many modeling methods for the rotor system. For example, the transfer matrix method (TMM) is used to derive the motion dynamics equation of the general rotor system [11]. On multirotor modal dynamics issue, Oliver et al. [12] proposed a novel method to establish a multirotor wind turbine model. In order to derive the motion equation of the multidisk and multilayer rotor-shaft system, a discrete method and lumped mass method were given by Roy [13]. The various components in the rotor system usually have a coupling relationship, which cause the model to be more complicated. So, Mereles and Cavalca [14] proposed a continuous segment method (CSM) to model a complex rotor system with multiple disks and bearings. This method divides the system into segments, which can solve the problems of each part, separately. In order to establish a system coupling model, transmission system under consideration of the gear-rotor bearing coupling relationship also was explored and quantified [15]. 
Usually, the connection and supporting parts in the rotor system have an important influence on the response of the system. The influence of shaft speed on bearing clearance was an important factor. The dynamic characteristics of the bearing-rotor system were analyzed by many scholars $[16,17]$. The centrifugal load or temperature referenced on the bearing stiffness, damping, and the influence of load capacity can be applied to any kind of rotor system supported by gas bearing. Nonlinear Control Equation for a dual-rotor system supported by ball bearings was often established as finite element method [18]. At the same time, the influence of bearing clearance on time-varying stiffness and main resonance behavior is analyzed in detail by numerical methods. For example, Novotný [19] proposed a new analytical and numerical calculation model for the rapid combination of thrust bearings, which verified the effectiveness of the model through Computational Fluid Dynamics (CFD) and technical experiments on actual exhaust gas turbochargers. At the connecting parts in the system, Li et al. [20] established a dynamic model of the rotor system with bolt-disk connection. Based on the dynamic model, Yu et al. [21] introduced the bolt joint model, which was used to study the dynamic characteristics of the bolt rotor. In addition, in order to explore the influence of the existence of friction on the rotor's self-selected speed and resonance characteristics, dual-rotor mathematical model that considered the friction coefficient and eccentricity between the stator and the rotor was established for the suspended rotor system [22]. Shin and Palazzolo [23] proposed a novel method for modeling and analyzing the gear-rotor bearing system. The dynamic model established by this method has five degrees of freedom.

The transmission system in the parallel rotating body has always been an important content of the research in the field of rotor dynamics. In order to explore the vibration of the gear transmission system, Choy et al. [24, 25] proposed a mathematical model that couples the gear-bearing-rotor system with the gearbox. The coupling of the transmission system makes the rotor system more complicated. Therefore, the analysis of the system requires a combination of multiple methods. Taghipour et al. [26] used the extended Hamilton principle to establish the nonlinear motion equation of the rotor system. At the same time, the hypothetical mode method discretization and Galerkin method are used to solve the obtained nonlinear control equations. Tatar et al. [27] combined the lumped parameter model of the planetary gearbox with the Finite Element Model of the rotating shaft using Timoshenko beams to create a dynamic model of a multi-degree-of-freedom system. Taherkhani and Ahmadian [28] used the parameter selection procedure of random model update and appropriate sampling strategy to study the variability in the dynamic behavior of complex turbo compressor rotor bearing support system. Subsequently, the Bayesian method was used to estimate the parameter uncertainty in rotor with speed-dependent characteristics. Through the Lagrangian method and global bifurcation analysis method, Cao studied the dynamic behavior of rotor blade system with NES [29].
In order to study the influence of transmission mode on the vibration response of combine harvester threshing system, this paper analyzes the influence of two transmission modes with unilateral transmission and bilateral transmission. The dynamic model of the parallel multidrum threshing system under two transmission modes is established. Through the model, the inherent characteristics of the threshing system are obtained. In addition, the model response under forced vibration is numerically analyzed. Finally, in order to verify the validity of the model, an experiment on the influence of the transmission mode on the vibration response of the parallel system is carried out through a proportional test bench.

\section{Materials and Methods}

2.1. Kinetic Model of Parallel Multidrum. The parallel multidrum threshing system on combine harvester generally includes multiple threshing drums, which are driven by chain drive or belt drive for power transmission. As shown in Figure 1, the power transmission method between them will be more flexible and complex depending on the actual installation position.

As a typical rotating working part, simplifying its transmission mode and modeling the dynamics of the transmission system is an important part for studying the vibration characteristics of the threshing system. Establishment of the system model adopts the lumped parameter method. By discretizing each component in the system into multiple continuous lumped disks and concentrated mass points, the mechanical relationship between each unit point is established. The relative position between each node is equivalent to a cantilever beam structure to establish the relationship between the displacement and force between its adjacent nodes, so that the discrete mass units are related to each other and form a whole.

Threshing drum can be simplified as a series of multiple massless rods and multiple discs. The relationship between adjacent disc cross sections $i$ and $i-1$ is shown in Figure 2 . The following relationship can be obtained from the force and moment relationship on the graph.

$$
\begin{aligned}
& N_{i}=N_{i-1}-Q_{i-1} l_{i}, \\
& Q_{i}=Q_{i-1},
\end{aligned}
$$

where $N_{i}$ is the bending moment of the $i$-th disc section; $Q_{i}$ is the sectional sheer force of the $i$-th disc; $l_{i}$ is the length of $i$-th axis. Then the shaft section between the two lumped parameter discs can be simplified into a cantilever beam structure. According to the deformation calculation equation of the material mechanics cantilever beam, the deformation of each section of the shaft can be obtained.

$$
\begin{gathered}
y=\frac{N_{i} l_{i}^{2}}{2 E J_{i}}+\frac{Q_{i} l_{i}^{3}}{3 E J_{i}}, \\
\theta=\frac{N_{i} l_{i}}{E J_{i}}+\frac{Q_{i} l_{i}^{2}}{2 E J_{i}},
\end{gathered}
$$




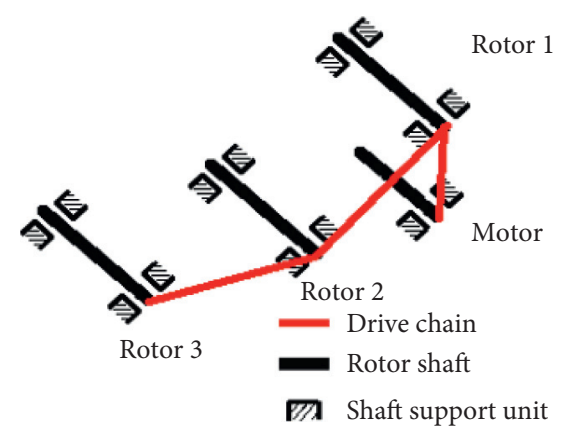

FIgURe 1: Parallel system unilateral transmission.

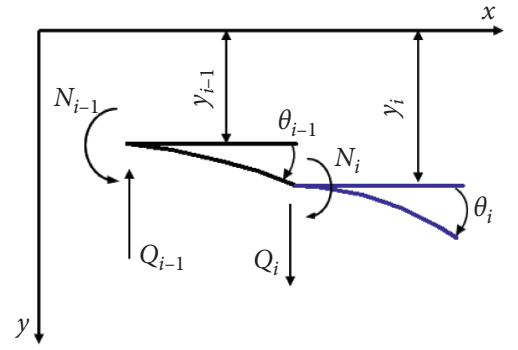

FIGURE 2: Relationship between adjacent cross section force and displacement.

where $y$ is sectional displacement; $\theta$ is sectional angle; $E$ is material modulus of elasticity; $J_{i}$ is moment of inertia of the rod in the $i$-th segment. Express equation (2) in the form of a matrix.

$$
\left(\begin{array}{c}
y \\
\theta \\
N \\
Q
\end{array}\right)_{i}=\left[\begin{array}{cccc}
1 & l & l^{2} /(2 E J) & -l^{3} /(6 E J) \\
0 & 1 & l /(E J) & -l^{2} /(2 E J) \\
0 & 0 & 1 & -l \\
0 & 0 & 0 & 1
\end{array}\right]_{i}\left(\begin{array}{c}
y \\
\theta \\
N \\
Q
\end{array}\right)_{i-1} .
$$

The transfer matrix from segment $i-1$ to segment $i$ can be expressed as

$$
A_{i}=\left[\begin{array}{cccc}
1 & l & l^{2} /(2 E J) & -l^{3} /(6 E J) \\
0 & 1 & l /(E J) & -l^{2} /(2 E J) \\
0 & 0 & 1 & -l \\
0 & 0 & 0 & 1
\end{array}\right]_{i}
$$

The state vector of each shaft section is $\{Z\}=\{y|\theta| N \mid Q\}^{T}$; the following equation can be obtained from the transfer relationship between sections $i$ and $i-1$.

$$
\left\{\begin{array}{c}
y \\
\theta \\
N \\
Q
\end{array}\right\}_{j}^{L}=\left[\begin{array}{cccc}
1 & h_{12} & h_{13} & h_{14} \\
0 & 1 & h_{23} & h_{24} \\
0 & 0 & 1 & h_{34} \\
0 & 0 & 0 & 0
\end{array}\right]_{j-1}\left\{\begin{array}{c}
y \\
\theta \\
N \\
Q
\end{array}\right\}_{j-1}^{R}
$$

where $h_{34}=-h_{12}, h_{13}-h_{24}=h_{12} h_{23}$.

According to the relationship between the cross-sectional displacement at both ends of the disc and the state vector of the rotation angle, we can obtain

$$
\left\{\begin{array}{l}
y \\
\theta
\end{array}\right\}^{L}=\left\{\begin{array}{l}
y \\
\theta
\end{array}\right\}^{R}=\left\{\begin{array}{l}
y \\
\theta
\end{array}\right\} .
$$

The schematic diagram of the force of the $j$-th disc is shown in Figure 3. $P_{y j}$ is the sum of the external forces in the yoz plane. According to the force balance, the following equation can be obtained:

$$
\left\{\begin{array}{l}
N \\
Q
\end{array}\right\}_{j}^{L}-\left\{\begin{array}{l}
N \\
Q
\end{array}\right\}_{j}^{R}=-\left\{\begin{array}{c}
0 \\
P_{y}
\end{array}\right\}_{j}
$$

Putting equations equation (5) and (6) into equation (7), we can get

$$
-\left[\begin{array}{ll}
g_{11} & g_{12} \\
g_{21} & g_{22}
\end{array}\right]_{j-1}\left\{\begin{array}{l}
y \\
\theta
\end{array}\right\}_{j-1}+\left\{\left[\begin{array}{ll}
b_{11} & b_{12} \\
b_{21} & b_{22}
\end{array}\right]_{j}+\left[\begin{array}{ll}
s_{11} & s_{12} \\
s_{21} & s_{22}
\end{array}\right]_{j-1}\right\}\left\{\begin{array}{l}
y \\
\theta
\end{array}\right\}_{j}-\left[\begin{array}{ll}
e_{11} & e_{12} \\
e_{21} & e_{22}
\end{array}\right]_{j}\left\{\begin{array}{l}
y \\
\theta
\end{array}\right\}_{j+1}=-\left\{\begin{array}{c}
0 \\
P_{y}
\end{array}\right\}_{j}
$$




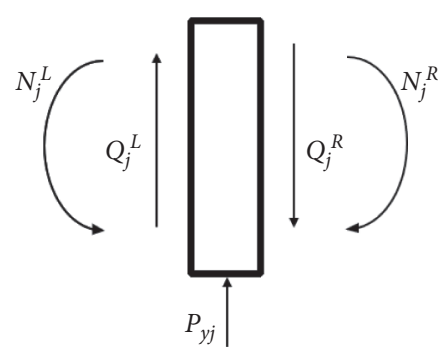

Figure 3: The force state of the $j$-th disc.

where $e_{11}=h_{24} / \Delta ; e_{12}=-h_{14} / \Delta ; e_{21}=-h_{23} / \Delta ; e_{22}=h_{13} / \Delta$; $b_{11}=e_{11} ; b_{12}=e_{12}+e_{11} h_{12} ; b_{21}=e_{21} ; b_{22}=e_{22}+e_{21} h_{12}$;

$\Delta=h_{13 h_{24}}-h_{23} h_{14} ; s_{11}=e_{11}+e_{21} h_{34} ; s_{12}=e_{12}+e_{22} h_{34} ; s_{21}$ $=e_{21} ; s_{22}=e_{22}$;

$$
\begin{aligned}
g_{11} & =b_{11}+b_{21} h_{34} ; g_{12}=b_{12}+b_{22} h_{34} ; g_{21}=b_{21} \\
& =e_{21} ; g_{22}=b_{22}=e_{11} .
\end{aligned}
$$

The discretization model of the threshing system is shown in Figure 4. Firstly, according to the above relationship, the relationship between the force and displacement between the various nodes in the mathematical model of the parallel multidrum system is expressed as

$$
\begin{aligned}
& -\left(\left[\begin{array}{cc}
1 & -l \\
0 & 1
\end{array}\right]\left[\begin{array}{cc}
l^{2} / 2 E J & -l^{3} / 6 E J \\
l / E J & -l^{2} / 2 E J
\end{array}\right]^{-1}\left[\begin{array}{ll}
1 & l \\
0 & 1
\end{array}\right]\right)_{j-1}\left\{\begin{array}{l}
y \\
\theta
\end{array}\right\}_{j-1}+\left[\left(\left[\begin{array}{cc}
1 & -l \\
0 & 1
\end{array}\right]\left[\begin{array}{cc}
l^{2} / 2 E J & -l^{3} / 6 E J \\
l / E J & -l^{2} / 2 E J
\end{array}\right]_{j-1}^{-1}\right)_{j}\right. \\
& +\left(\left[\begin{array}{cc}
l^{2} / 2 E J & -l^{3} / 6 E J \\
l / E J & -l^{2} / 2 E J
\end{array}\right]^{-1}\left[\begin{array}{ll}
1 & l \\
0 & 1
\end{array}\right]_{j}\right]\left\{\begin{array}{l}
y \\
\theta
\end{array}\right\}_{j}+\left[\begin{array}{rr}
l^{2} / 2 E J & -l^{3} / 6 E J \\
l / E J & -l^{2} / 2 E J
\end{array}\right]_{j}^{-1}\left\{\begin{array}{l}
y \\
\theta
\end{array}\right\}_{j+1}=-\left\{\begin{array}{c}
0 \\
P_{y}
\end{array}\right\}_{j} .
\end{aligned}
$$

From equation (10), we can get

$$
\begin{aligned}
& K_{11}\{y\}+K_{12}\{\theta\}=\{0\}, \\
& K_{21}\{y\}+K_{22}\{\theta\}=-\left\{P_{y}\right\},
\end{aligned}
$$

where $K_{11}=K_{22}{ }^{T},\{y\}=\left\{y_{1}, y_{2} \ldots y_{n}\right\}^{T}, \quad\{\theta\}=\left\{\theta_{1}, \theta_{2} \ldots\right.$ $\left.\theta_{n}\right\}^{T}$, and $\left\{P_{y}\right\}=\left\{P_{y_{1}}, P_{y_{2}} \ldots P_{y_{n}}\right\}^{T}$.

From the above,

$$
\left(K_{21}-K_{22} \bullet K_{12} \bullet K_{22}{ }^{T}\right)\{Y\}=-\left\{P_{y}\right\} .
$$

Let $\mathrm{K}=\left(K_{21}-K_{22} \bullet K_{12} \bullet K_{22}{ }^{T}\right)$ to get

$$
[K]\{Y\}+\left\{P_{y}\right\}=\{0\} .
$$

Let

$$
K_{i j}=\left[\begin{array}{llll}
A_{i j} & & & \\
& B_{i j} & & \\
& & C_{i j} & \\
& & & D_{i j}
\end{array}\right] .
$$

$\left\{P_{y}\right\}$ can be expressed as

$$
\left\{P_{y}\right\}=[M]\{\ddot{Y}\}+\left[D^{\prime}\right]\{\dot{Y}\}+\left[K^{\prime}\right]\{Y\}-\omega^{2}\left\{F_{Y}\right\},
$$

which is

$$
[M]\{\ddot{Y}\}+\left[D^{\prime}\right]\{\dot{Y}\}+\left[K^{\prime}\right]+[K]\{Y\}=\left\{\omega^{2} F_{Y}\right\} .
$$

Similarly in the $x$ plane,

$$
\begin{aligned}
& {[M]\{\ddot{X}\}+\left[D^{\prime}\right]\{\dot{X}\}+\left(\left[K^{\prime}\right]+[K]\right)\{X\}+\left[D^{\prime}\right]\left\{\dot{X}^{\prime}\right\}} \\
& +\left[K^{\prime}\right]\left\{X^{\prime}\right\}=\left\{\omega^{2} F_{X}\right\},
\end{aligned}
$$

where the quality matrix is $M=\operatorname{diag}\left[m_{1}, m_{2}, \ldots, m_{i}\right.$, $\left.\ldots, m_{26}\right],(i=1,2,3, \ldots \ldots, 26)$. The state parameter is $\{\ddot{X}\}=\left[\ddot{X}_{1}, \ddot{X}_{2}, \ddot{X}_{3}, \ddot{X}_{4}\right]^{T}, \quad\{\dot{X}\}=\left[\dot{X}_{1}, \dot{X}_{2}, \dot{X}_{3}, \dot{X}_{4}\right]^{T}, \quad$ and $\{X\}=\left[X_{1}, X_{2}, X_{3}, X_{4}\right]^{T}$. Each component can be expressed as

$$
\begin{aligned}
& \left\{\ddot{x}_{1}\right\}=\left[\ddot{x}_{11}, \ddot{x}_{12}, \ddot{x}_{13}, \ddot{x}_{14}, \ddot{x}_{15}\right]^{T},\left\{\ddot{x}_{2}\right\}=\left[\ddot{x}_{21}, \ddot{x}_{22}, \ddot{x}_{23}, \ddot{x}_{24}, \ddot{x}_{25}, \ddot{x}_{26}, \ddot{x}_{27}\right]^{T}, \\
& \left\{\ddot{x}_{3}\right\}=\left[\ddot{x}_{31}, \ddot{x}_{32}, \ddot{x}_{33}, \ddot{x}_{34}, \ddot{x}_{35}, \ddot{x}_{36}, \ddot{x}_{37}\right]^{T},\left\{\ddot{x}_{4}\right\}=\left[\ddot{x}_{41}, \ddot{x}_{42}, \ddot{x}_{43}, \ddot{x}_{44}, \ddot{x}_{45}, \ddot{x}_{46}, \ddot{x}_{47}\right]^{T},
\end{aligned}
$$




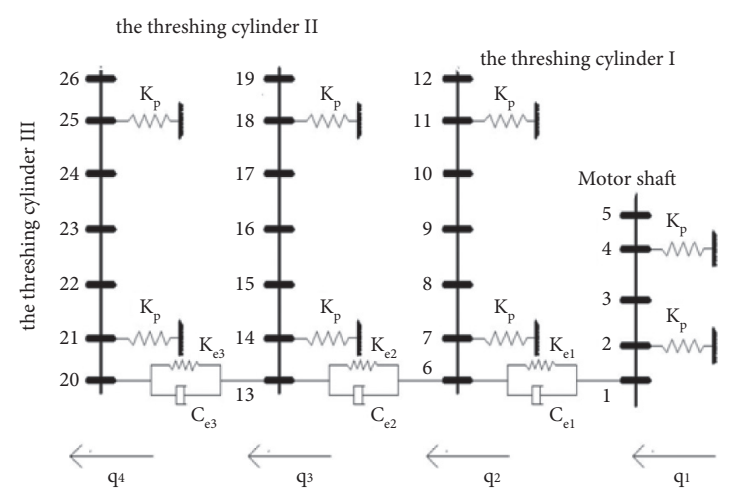

(a)

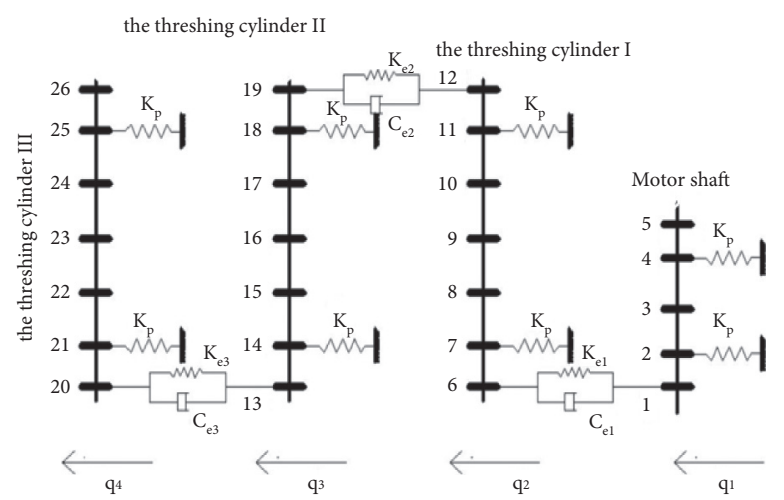

(b)

Figure 4: Simplified model of parallel threshing system. (a) Unilateral transmission. (b) Bilateral transmission.

$$
\begin{aligned}
& \left\{\dot{X}_{1}\right\}=\left[\dot{x}_{11}, \dot{x}_{12}, \dot{x}_{13}, \dot{x}_{14}, \dot{x}_{15}\right]^{T},\left\{\dot{X}_{2}\right\}=\left[\dot{x}_{21}, \dot{x}_{22}, \dot{x}_{23}, \dot{x}_{24}, \dot{x}_{25}, \dot{x}_{26}, \dot{x}_{27}\right]^{T}, \\
& \left\{\dot{X}_{3}\right\}=\left[\dot{x}_{31}, \dot{x}_{32}, \dot{x}_{33}, \dot{x}_{34}, \dot{x}_{35}, \dot{x}_{36}, \dot{x}_{37}\right]^{T},\left\{\dot{X}_{4}\right\}=\left[\dot{x}_{41}, \dot{x}_{42}, \dot{x}_{43}, \dot{x}_{44}, \dot{x}_{45}, \dot{x}_{46}, \dot{x}_{47}\right]^{T}, \\
& \left\{X_{1}\right\}=\left[x_{11}, x_{12}, x_{13}, x_{14}, x_{15}\right]^{T},\left\{X_{2}\right\}=\left[x_{21}, x_{22}, x_{23}, x_{24}, x_{25}, x_{26}, x_{27}\right]^{T}, \\
& \left\{X_{3}\right\}=\left[x_{31}, x_{32}, x_{33}, x_{34}, x_{35}, x_{36}, x_{37}\right]^{T} ;\left\{X_{4}\right\}=\left[x_{41}, x_{42}, x_{43}, x_{44}, x_{45}, x_{46}, x_{47}\right]^{T} .
\end{aligned}
$$

For the unilateral transmission system, the main difference of the bilateral transmission system is that the force and transmission of the lumped discs 6, 12, 13, and 19 are changed, so the force analysis of these lumped discs is carried out. The transmission relationship and force conditions of other positions are the same as the three-roller unilateral transmission. At the same time, its internal stiffness matrix and damping matrix have undergone certain changes.

\subsection{Equivalent Tensile Stiffness of Transmission Chain.} Due to the polygonal effect of the chain in the actual working process, the phenomenon of "short-term looseness" will appear in the process of transmitting power. Therefore, there will be a certain error when the state of the chain is completely equivalent to a rigid rod. Based on the above assumptions, this paper considers that the tight sides of the chain are connected by a series of rigid bars. The physical model is shown in Figure 5(a).

According to the above analysis, the chain can be equivalent to the dynamic model shown in Figure 5(b). The outer chain and the inner chain of the chain are equivalent to a series of rigid rods. The rigid rods have a certain stiffness coefficient. They are connected by rigidity and damping elements. The stiffness values on the outer chain and the inner chain can be calculated. It is equivalent to the connection key between them for calculation and analysis.

Taking the commonly used chains on the combine harvester as the research object, the tensile stiffness of the chain is solved by the finite element method. The drive chain includes two models, $08 \mathrm{~B}-1$ and $12 \mathrm{~A}-1$, and the model of the chain connecting drum II and drum III is also 08B-1. Therefore, the actual calculation and simulation only need to simulate and solve the tensile stiffness of the two types of chain links, including the outer chain and the inner chain. Both chains are made of high-quality No. 45 carbon structural steel, which has the advantages of high strength, high hardness, good wear resistance, and high resistance to deformation. The specific parameters of the two types of chains are shown in Table 1.

According to the above parameters, the chain link is modeled by the three-dimensional software Pro/E. Taking the model of the $08 \mathrm{~B}-1$ outer chain and the inner chain as an example, the three-dimensional structure is shown in Figure 6.

2.3. Experimental Designs. The boundary conditions of the parallel multidrum system will be affected by the transmission system, which will cause the amplitude and phase of its vibration to be different from the vibration response of a single drum when it is working. Therefore, in order to further verify the validity of the numerical calculation results, a multiroller test bench is used as the research object to analyze the influence of different transmission modes and boundary conditions on the response of the system. Vibration test experiment of parallel system is shown in Figure 7. Finally, further analysis and verification are carried out based on the result of the unbalanced response calculated by the numerical value.

In the experiment, an unbalanced mass was applied to the same position of the drum, and the influence of the change of the transmission mode on the vibration response of the system was analyzed by changing the transmission mode and boundary conditions. In order to ensure the comparability of the test, under the two transmission modes, 


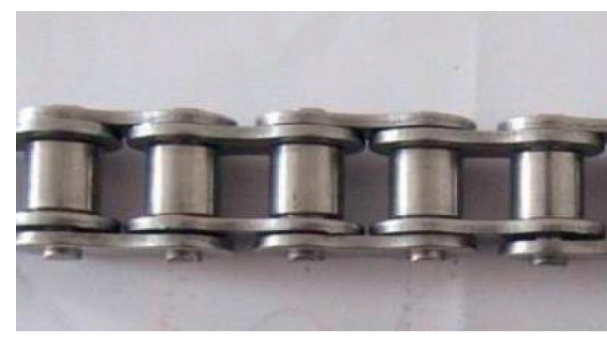

(a)

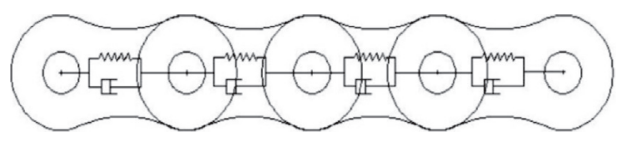

(b)

Figure 5: Transmission chain equivalent model. (a) Physical model of chain. (b) Equivalent dynamic model of chain.

TABle 1: Parameters of transmission chain.

\begin{tabular}{lccccc}
\hline Type & Pitch $(\mathrm{mm})$ & Pin shaft length $(\mathrm{mm})$ & Inner section width $(\mathrm{mm})$ & Roller diameter $(\mathrm{mm})$ & Ultimate load $(\mathrm{t})$ \\
\hline 08B-1 & 12.7 & 16.7 & 7.75 & 8.51 & 1.8 \\
$12 \mathrm{~A}-1$ & 19 & 25.9 & 12.57 & 11.91 & 3.1 \\
\hline
\end{tabular}

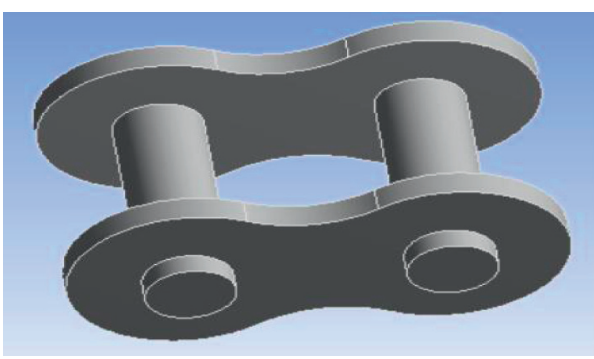

(a)

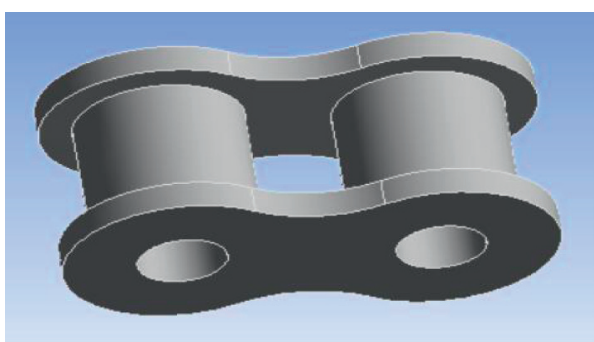

(b)

FIgURE 6: (08B-1) Three-dimensional model of the chain. (a) 08B-1 model of outer chain and (b) 08B-1 model of inner chain.

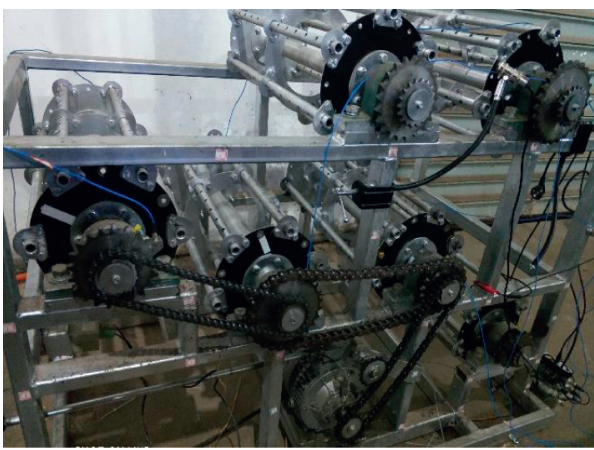

(a)

FIGURE 7: Vibration test experiment of parallel system

the position of the vibration acceleration sensor remained unchanged. During the test, the threshing drum I included a total of 6 speeds, which increased by $50 \mathrm{r} / \mathrm{min}$ from $550 \mathrm{r} /$ $\mathrm{min}$ to $800 \mathrm{r} / \mathrm{min}$ each time. There are 10 counterweight holes on the rack of drum I, and these 10 counterweight holes are symmetrical with respect to the frame in the middle of drum I. During the test, the same unbalanced mass was sequentially applied to the counterweight holes. The specific unbalanced mass size was $383.32 \mathrm{~g}$. The method of applying

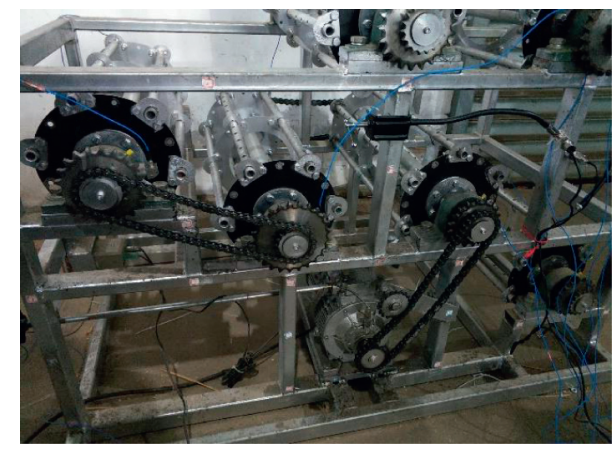

(b)

(a) Unilateral transmission. (b) Double-sided transmission.

the unbalanced mass and the location of each counterweight hole are shown in Figures 8 and 9.

\section{Results and Discussion}

3.1. Dynamic Model of Multidrum Threshing System in Parallel. Chain is statically analyzed by ANSYS, and the material of the chain is set to 45 steel. After the setting is completed, the corresponding mesh is divided, and the 


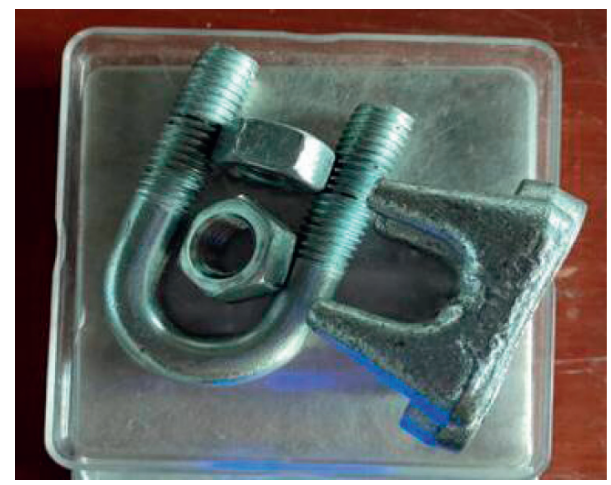

Figure 8: Weighing of unbalanced mass.

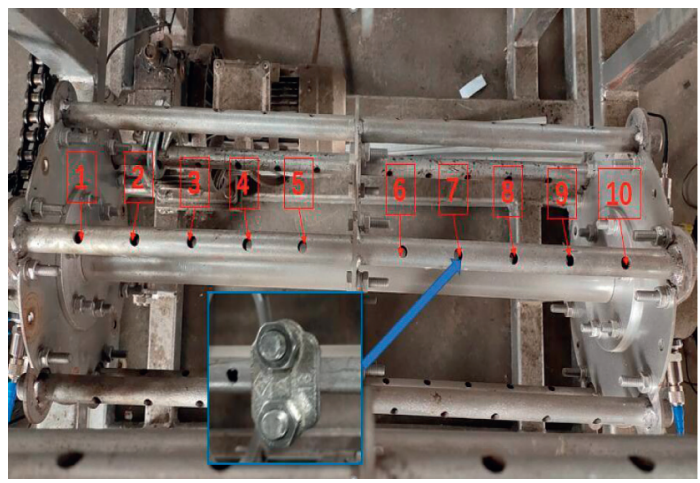

Figure 9: Position of the axial counterweight hole.

tetrahedral free division mode is selected when dividing. Taking the 08B-1 chain as an example, the result of meshing is shown in Figure 10. Figure 10(a) is the grid division result of outer chain; Figure 10(b) is the grid division result of inner chain.

In the simulation, the force of $20 \mathrm{kN}$ is applied to $08 \mathrm{~B}-1$ and the force of $10 \mathrm{kN}$ is applied to $12 \mathrm{~A}-1$. The result of static stretching and the simulation result of the chain are shown in Figure 11.

The simulation results show that the maximum deformation of the mother chain of the 08B-1 chain is $0.037397 \mathrm{~mm}$ and $-0.035102 \mathrm{~mm}$. The maximum deformation of the outer chain is $0.17678 \mathrm{~mm}$ and $-0.17919 \mathrm{~mm}$. The maximum deformation of the $12 \mathrm{~A}-1$ inner chain is $0.012777 \mathrm{~mm}$ and $-0.012481 \mathrm{~mm}$. The maximum deformation of the outer chain is $0.09016 \mathrm{~mm}$ and $-0.091455 \mathrm{~mm}$. In actual work, the loose side of the chain does not perform power transmission, so only the number of chain on the tight side needs to be calculated. According to the layout of the transmission chain in the threshing system, the equivalent tensile stiffness of the 08B-1 chain can be estimated to be $2.6674 \times 10^{6} \mathrm{~N} / \mathrm{m}$; the equivalent tensile stiffness of the $12 \mathrm{~A}$ 1 chain is $4.8339 \times 10^{6} \mathrm{~N} / \mathrm{m}$.

3.2. Vibration Mode Solution of Parallel Multidrum Threshing System. In order to analyze the modal characteristics of parallel multidrum threshing system, according to equation (17), insert $[\mathrm{M}],\left[\mathrm{D}^{\prime}\right],\left[\mathrm{K}^{\prime}\right],[\mathrm{K}]$, set $\omega^{2} F_{X}=0$, and the first four modes of the system are shown in Figure 12. It can be seen under the first-order vibration mode of the system that the modes of drum I and drum III are consistent, while the mode of drum II has the opposite direction. Under the second-order mode, each threshing drum in the threshing drum system vibrates, and the vibration mode of each drum tends to be the same. It can be seen from the third-order mode that the resonant units at this time are mainly drum I and drum III. The modes of them are basically the same and symmetrical about the coordinate axis. The vibration induced by drum II is relatively small. The fourth-order mode shows that drum II and drum III are symmetrical about the coordinate axis.

The results obtained by separately calculating the vibration modes of the motor shaft and drum II in the thirdorder state are shown in Figures 13 and 14.

It can be seen from Figure 13 that the mode of the motor shaft at this speed is consistent with the second-order mode, but the amplitude is smaller. Meanwhile, it can be seen from Figure 14 that the mode of drum II at this speed is consistent with the mode of the fourth-order critical speed, and mode of the drum II at the third-order critical speed is also stimulated.

\subsection{Analysis of Unbalanced Response under Forced Vibration}

3.3.1. Parallel System under Unilateral Transmission. The speeds of the motor, drum I, drum II, and drum III are 


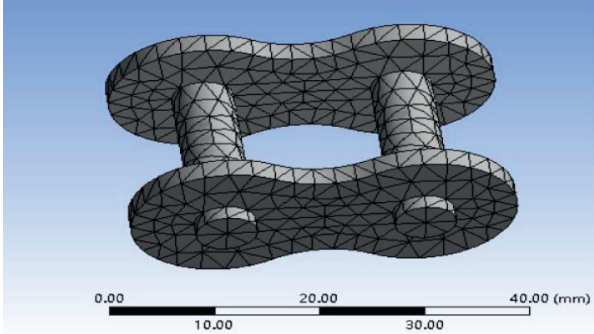

(a)

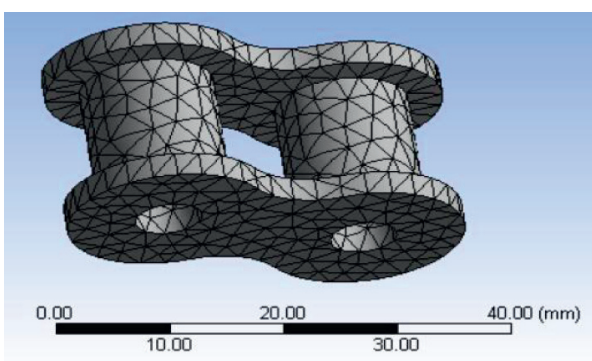

(b)

Figure 10: Meshing results of chain. (a) Meshing of outer chain. (b) Meshing of inner chain.

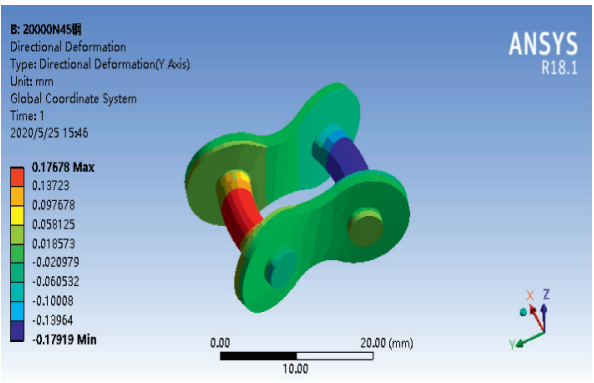

(a)

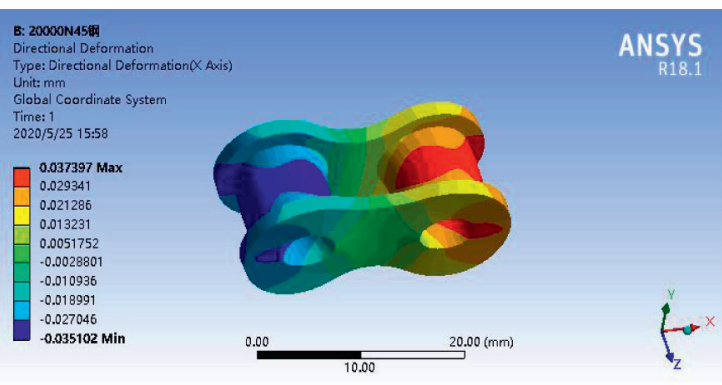

(b)

Figure 11: The simulation result of the chain. (a) Outer chain. (b) Inner chain.

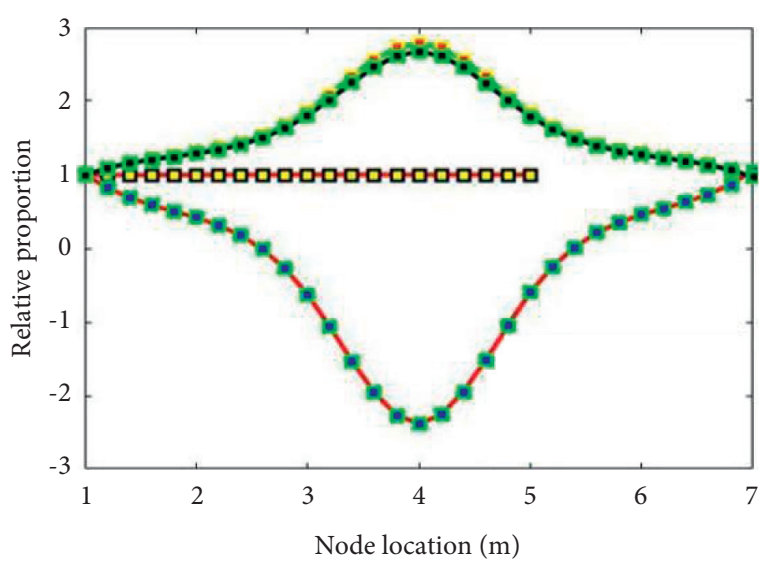

$\begin{array}{ll}-\square-\text { Motor shaft } & -\square-\text { threshing cylinder II } \\ -\square-\text { threshing cylinder I } & -\square-\text { threshing cylinder III }\end{array}$

(a)

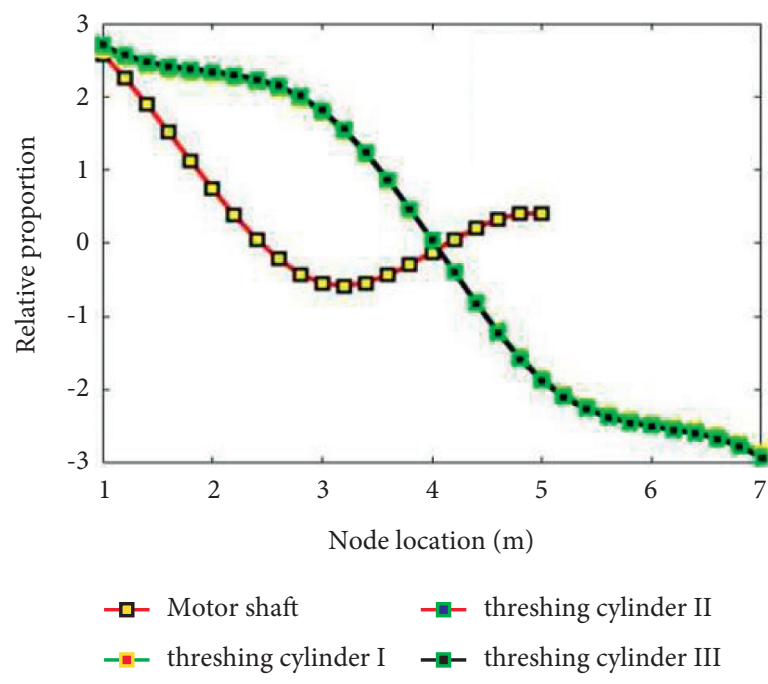

(b)

FIgURe 12: Continued. 


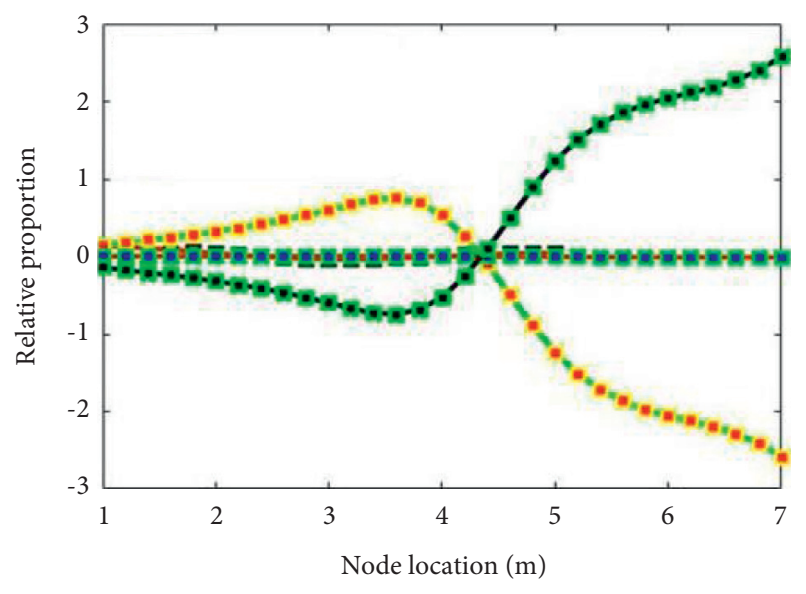

$\rightarrow-$ Motor shaft $\quad-\quad-$ -

-匹- threshing cylinder I - - - - threshing cylinder III

(c)

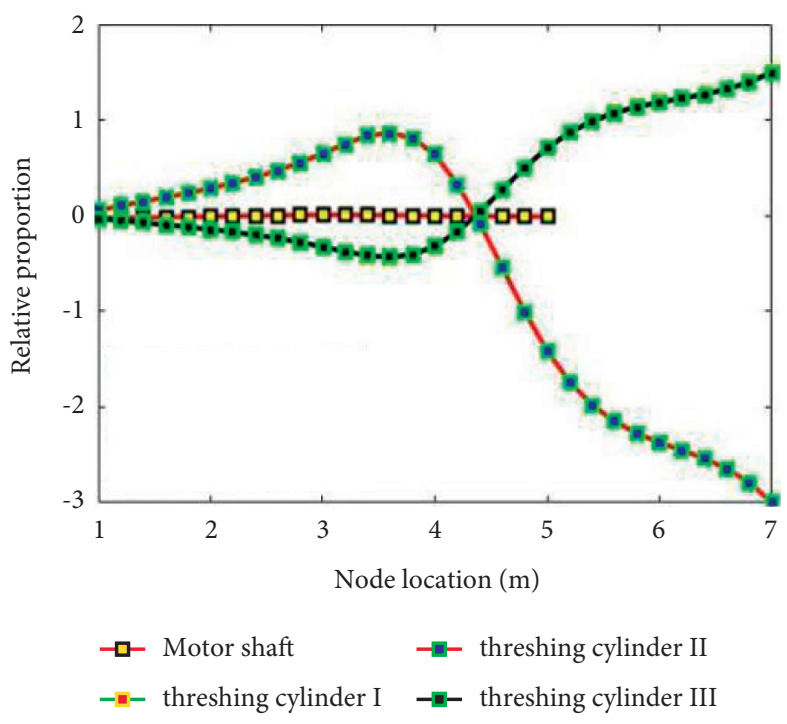

(d)

FIGURE 12: Mode of multidrum threshing system in parallel. (a) First-order mode, (b) second-order mode, (c) third-order mode, and (d) fourth-order mode.

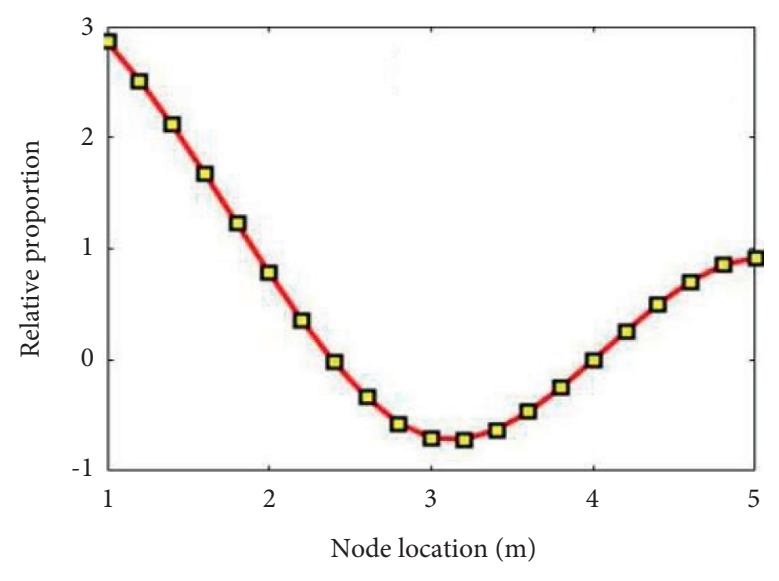

$\rightarrow-$ Motor shaft

Figure 13: Vibration modes of the motor shaft.

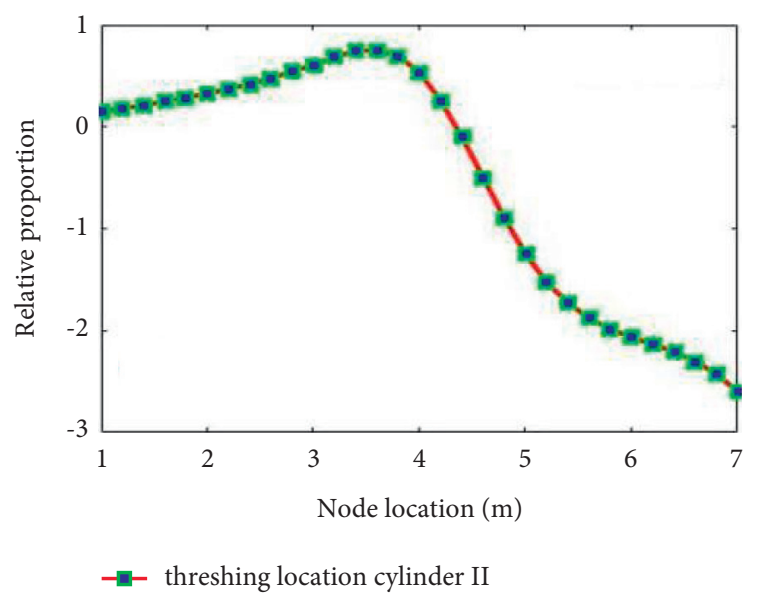

FIgURE 14: Vibration modes of threshing drum II. 
$10 \mathrm{rad} / \mathrm{s}, 20 \mathrm{rad} / \mathrm{s}, 30 \mathrm{rad} / \mathrm{s}$, and $40 \mathrm{rad} / \mathrm{s}$, respectively. Apply an unbalanced excitation of $2 \mathrm{~kg} \bullet \mathrm{mm}$ to the second node of each threshing drum near one end of the transmission chain. The vibration shape of each unit in the system obtained under unbalanced excitation is shown in Figure 15. The frequency domain characteristics of each node are shown in Figure 16.

It can be seen from the mode shape of the unbalanced response in Figures 15 and 16 that the mode response of the rollers of the same structure in the system under the same excitation is not the same because the existence of the transmission chain changes the boundary conditions. For analyzing the internal coupling characteristics of the parallel multidrum system, the parallel multidrum system is classified according to the rotation unit and the time-domain characteristics of each node in the parallel multidrum system are solved. The time-domain unbalanced response of each node of parallel system with unilateral transmission is shown in Figure 17.

From the time-domain unbalanced response of each node in Figure 17, it can be seen that the displacement response at each node is a superposition of multiple timedomain signals. The unbalanced response on the motor shaft is that the excitation source realizes the transmission of the vibration response through the stiffness characteristics of the transmission chain. Since the rigidity of the motor shaft itself is relatively small, the amplitude of its unbalanced response is relatively large. It can be seen that the coupling effect of the transmission chain can be ignored when the rigidity of the system itself is large or there is a large unbalanced excitation on it. When there are units with less rigidity in the system, the unbalanced response characteristics transmitted by the transmission chain are more obvious.

In order to carry further simulation analysis, motor speed is set to $100 \mathrm{rad} / \mathrm{s}$. According to the transmission relationship, the speed of drum I is set to $120 \mathrm{rad} / \mathrm{s}$; the speed of drum II is set to $80 \mathrm{rad} / \mathrm{s}$; the speed of drum III is set to $140 \mathrm{rad} / \mathrm{s}$. The unbalanced excitation is the same as it is at low speed. The unbalanced response of each work unit can be obtained by solving. Taking the time-domain characteristics of the motor shaft and drum III as an example, the results are shown in Figures 18 and 19. The frequency domain characteristics of each unit in the system are analyzed. The unbalanced response characteristics in the frequency domain are shown in Figure 20.

Each unit in the system forms a whole through the transmission chain. The unbalanced response of each moving unit superimposes and influences each other, which increases the unbalanced response range of the entire system. It can be seen from the frequency domain signal of the nodes that each node contains multiple frequency components consistent with the rotation speed of each threshing drum, indicating that the coupling of the transmission chain makes each component constitute the entire system. It can be seen from the time-domain analysis that the degree of influence of the transmission chain is related to the coupling stiffness and the object of action. The motion unit where the excitation source is located is less affected by the coupling characteristics of the chain drive, while other motion units are more affected by the coupling characteristics of the chain drive.

3.3.2. Parallel System under Bilateral Transmission. On the basis of the existing parameters, the unbalanced response characteristics of the bilateral transmission are solved and analyzed. The results of the solution are compared with those under the unilateral transmission. The mode response of the system under bilateral transmission is shown in Figure 21. The frequency domain response is shown in Figure 22.

It can be seen from Figures 21 and 22 that the change of the transmission has an obvious impact on the unbalanced response amplitude of the system. The mode response under bilateral transmission is relatively stable. It can be seen from the comparison of Figure 23 that, except for the small change in the unbalanced response of the motor shaft, the unbalanced response of the other threshing drums is affected by the change in the transmission mode. From the comparison of the time-domain unbalance response in Figure 23(b), it is found that the maximum unbalance response position of drum I under unilateral transmission is located at node 6 . This position is close to the excitation point of the system and is located on the coupling matrix of the transmission chain. The maximum unbalanced response position of the lower roller I of the bilateral transmission is at the node 10 position, which is located between the transmission chain and the excitation unit.

The main reason for this phenomenon is that the change of the transmission mode makes the excitation unit on other drums mainly transmitted to the node 12 position in the drum I through the coupling unit on the transmission chain. This position is close to the rolling bearing, so its imbalance response is not large and the position is far away from the excitation point on the drum I. The unbalanced response of the other rollers is transmitted through the rotating shaft and is superimposed with the unbalanced response generated on the roller I. Finally, it reaches the maximum position at node 10 where the stiffness is small. In order to further explain the transmission path of this vibration response, the frequency domain signal of each unit in the system under the parallel multidrum double-sided transmission is solved to obtain the FFT signal as shown in Figure 24.

The maximum response is at node 1 , which is connected to other rotating units through a transmission chain. The response of other working parts is transmitted to the motor shaft through the coupling unit on the transmission chain. As the stiffness decreases, the unbalanced response of the motor shaft mainly comes from the drum I. In addition, because the excitation point on drum II is far away from the transmission chain and the excitation energy on drum II is much smaller than drum III, the unbalanced response component of drum I is mainly the excitation component of drum III and its own unbalanced response component. Meanwhile, the unbalanced response component of roller II mainly comes from its own excitation and the excitation of roller III. For the drum III, the main component of its vibration response comes from its own dynamic imbalance. 


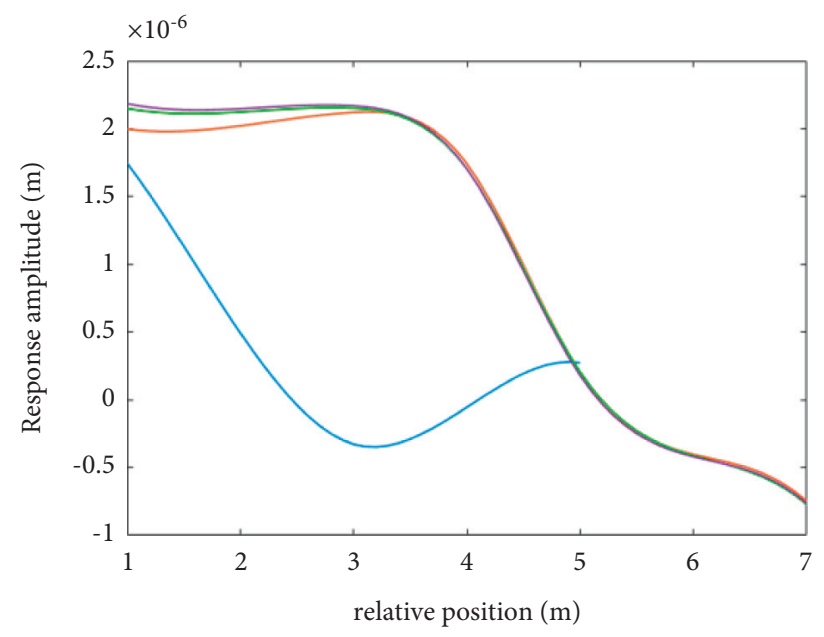

$\begin{array}{ll}\text { — Motor shaft } & \text { - threshing cylinder II } \\ \text { — threshing cylinder I } & \text { — threshing cylinder III }\end{array}$

Figure 15: Mode response of parallel system.

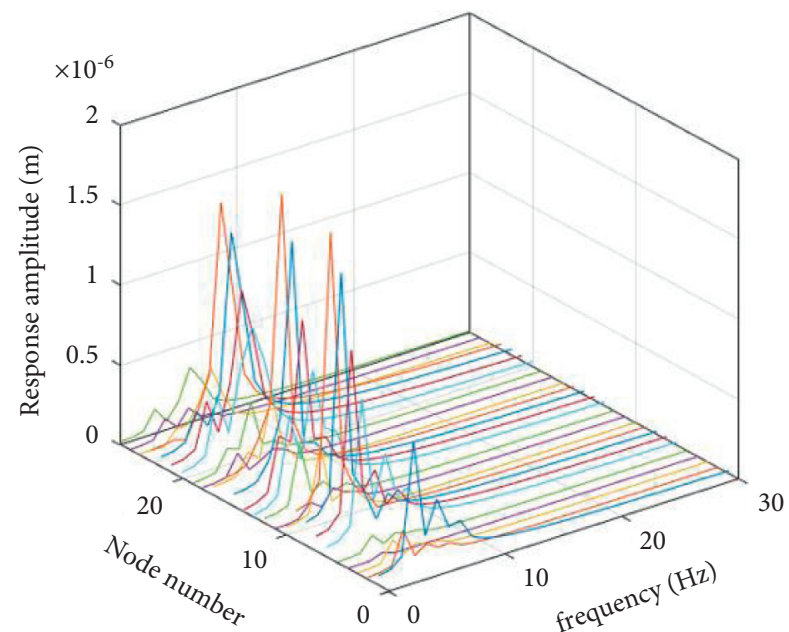

FIGURE 16: Frequency domain characteristics of each node.
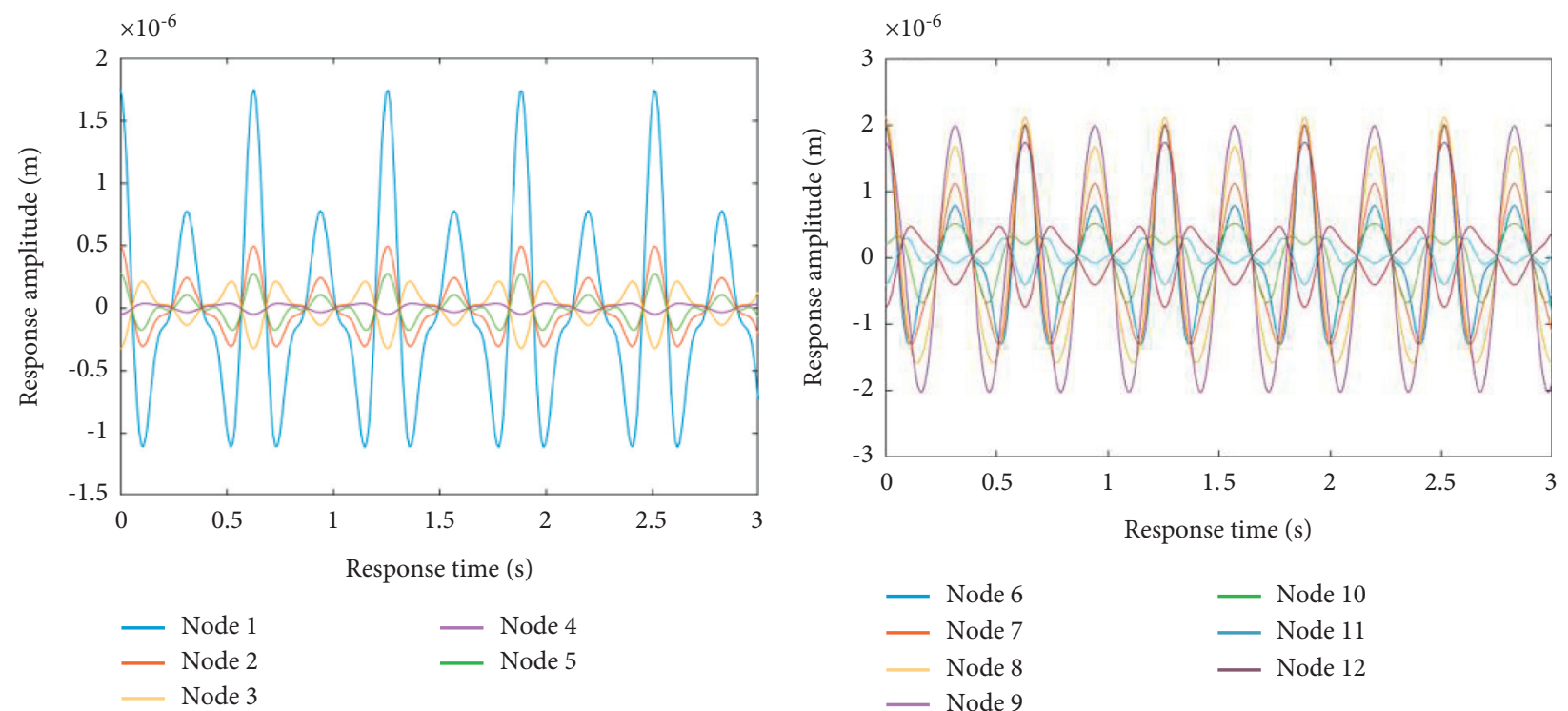

(a) 

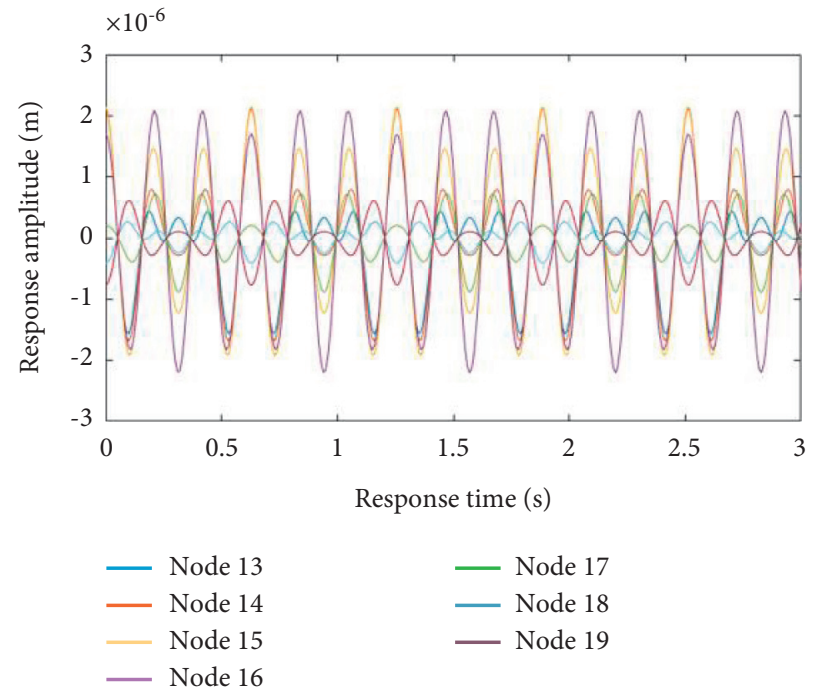

(c)

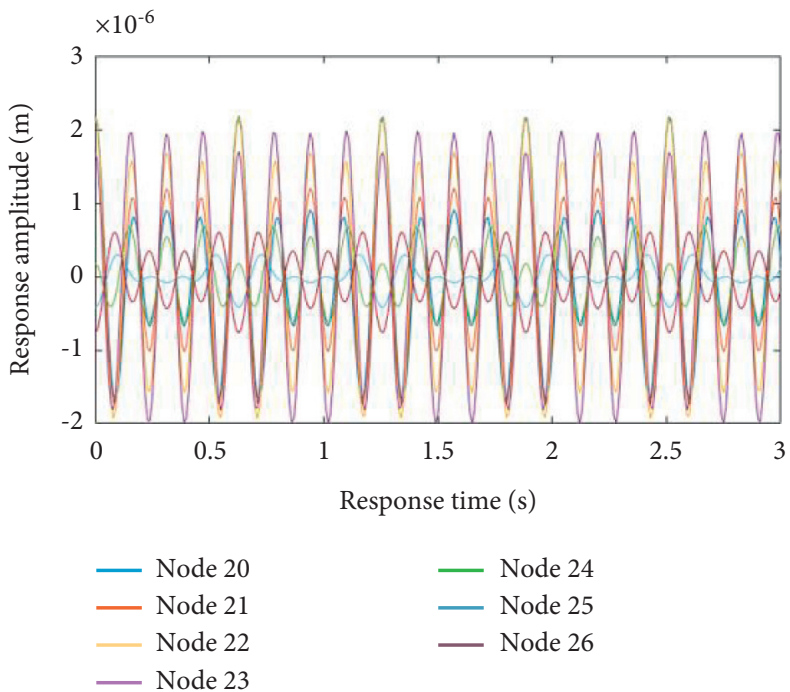

(d)

FIGURE 17: Time-domain response of parallel system with unilateral transmission. (a) Motor shaft, (b) threshing cylinder I, (c) threshing cylinder II, and (d) threshing cylinder III.

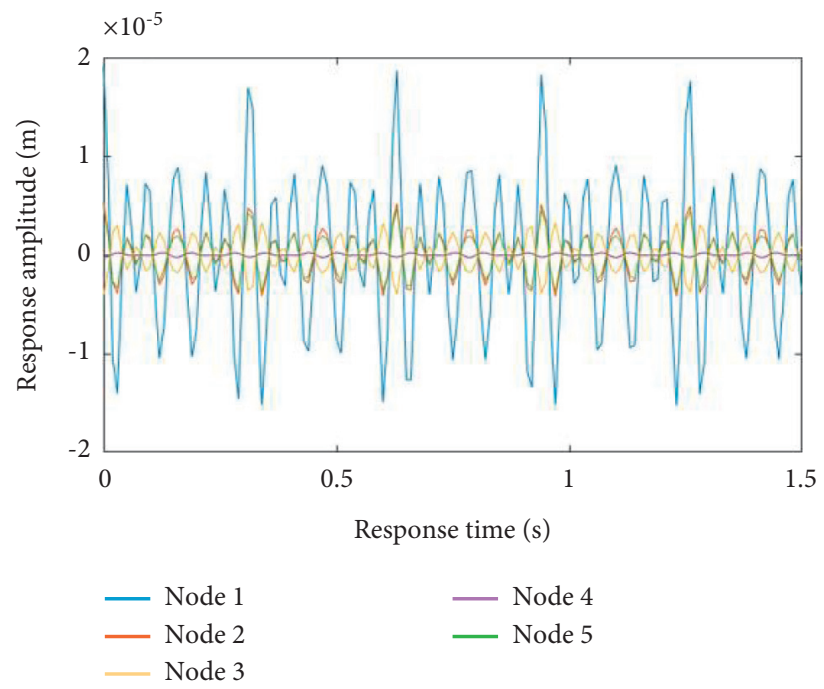

Figure 18: Time-domain response of the motor shaft.

3.4. Analysis of Unilateral Transmission Test Results. The speed increment under unilateral transmission is $50 \mathrm{r} / \mathrm{min}$ each time, and the measured system vibration response amplitude is shown in Tables 2, 3 .

It can be seen from the table that when the mass of the counterweight changes from position 1 to position 10 , the vibration response of the bearing seat position at the same speed changes nonlinearly. It may have a certain relationship with the structure of the threshing drum. There is a fixed and supporting web in the middle of the threshing drum, which makes the rigidity of the whole threshing drum uneven, which in turn leads to vibrations response fluctuating greatly when weight is placed at positions 4 to 7 .

In order to analyze the influence of the existence of the transmission chain on the axial vibration of the threshing drum, the unbalanced response amplitude data after the axial counterweight during unilateral transmission is processed. The amplitude change curve of the left end bearing seat position is shown in Figure 25.

The vibration amplitude change curve of the right end bearing seat is shown in Figure 26. Comparing the results of the unbalance response amplitude of the system as the counterweight position changes under different working conditions, it can be seen that even if the symmetrical position on the threshing drum is used as the excitation point, the presence of side transmission will cause the imbalance produced at the same position. There are certain differences in response.

Comparing the vibration magnitudes of the frequency domain signals obtained from the test data in various 


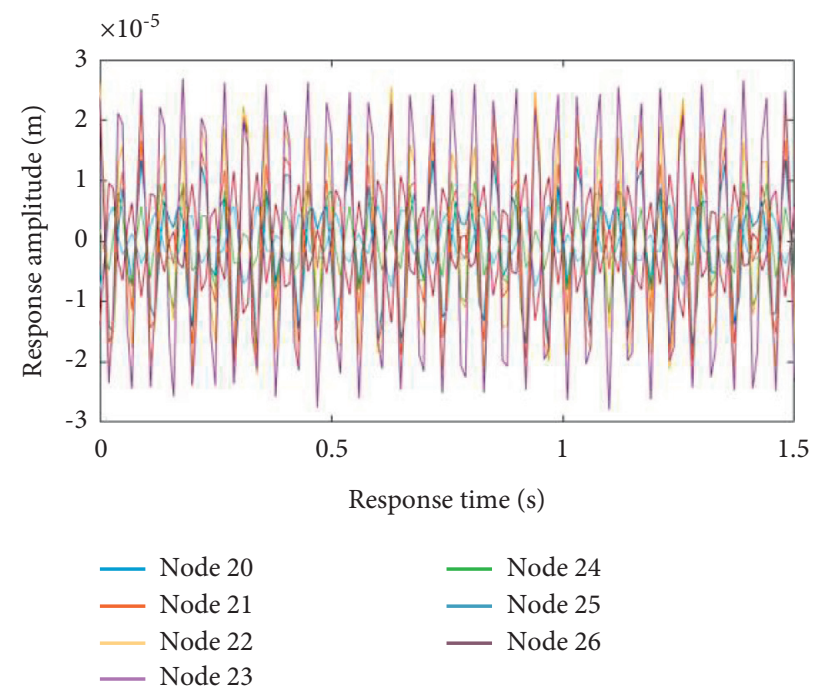

FIgURE 19: Time-domain response of threshing drum III.
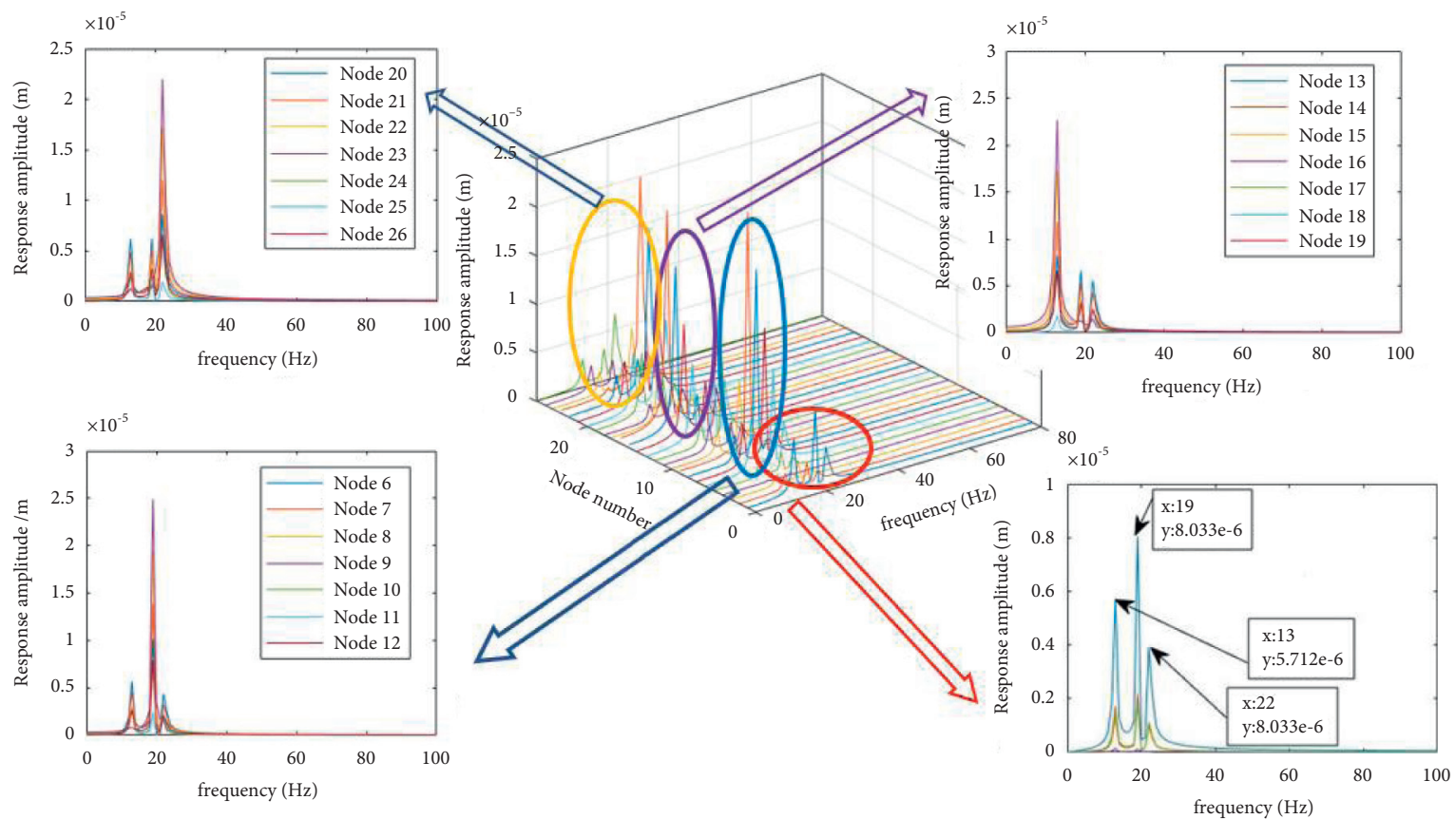

FIgURE 20: Frequency domain of vibration response of unilateral transmission.

directions at the fundamental frequency, it is found that the greater vibration direction of the system at its fundamental frequency is in the same direction, which makes the data under various working conditions have a certain degree of comparability. Take the frequency domain data when the roller I is working alone at the 1st and 10th positions and the rotation speed is $600 \mathrm{r} / \mathrm{min}$. The frequency domain data is analyzed, and the signals of the corresponding channels are Fourier transformed. The results are shown in Figures 27 and 28.
It can be seen from Figures 27 and 28 that since the speed of the threshing drum is $600 \mathrm{r} / \mathrm{min}$ in both working conditions, the fundamental frequency in the response of the bearing seat at the left end of the No. 1 position is the same as that of the No. 10 position, which is $10.01 \mathrm{~Hz}$. The vibration amplitude at the fundamental frequency excited by the left end bearing seat at No. 1 position is $0.187 \mathrm{~m} / \mathrm{s}^{2}$. The vibration amplitude at the fundamental frequency excited by the left end bearing seat at No. 10 position is $0.078 \mathrm{~m} / \mathrm{s}^{2}$. 


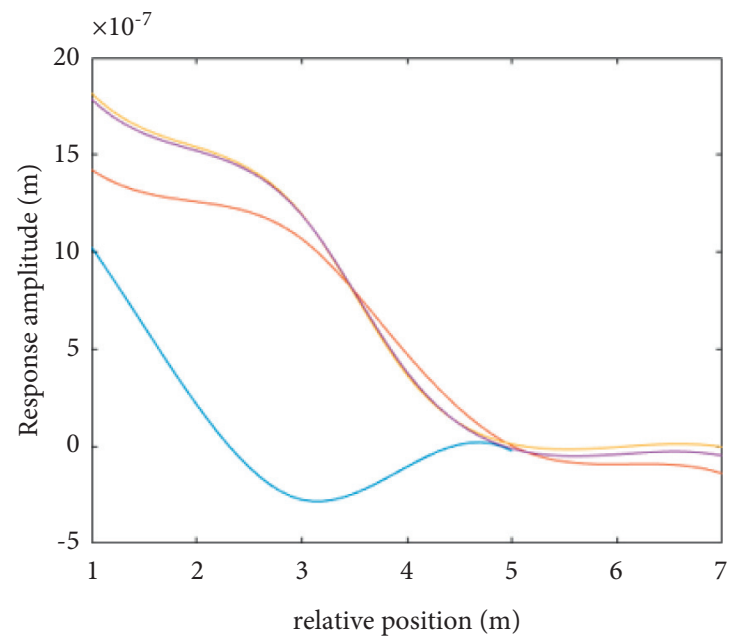

$\begin{array}{ll}\text { - Motor shaft } & \text { threshing cylinder II } \\ \text { — threshing cylinder I } \quad \text { - threshing cylinder III }\end{array}$

Figure 21: Mode response of parallel system.

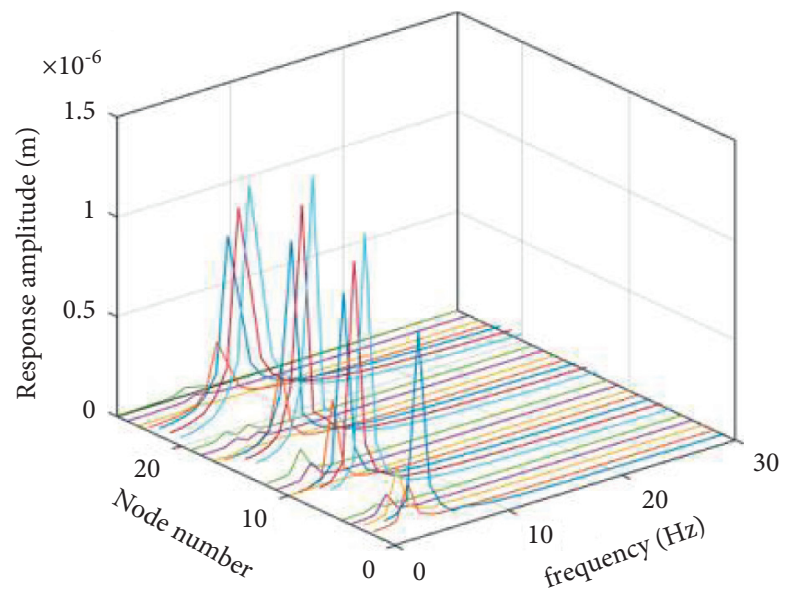

FIGURE 22: Frequency domain characteristics of each node.
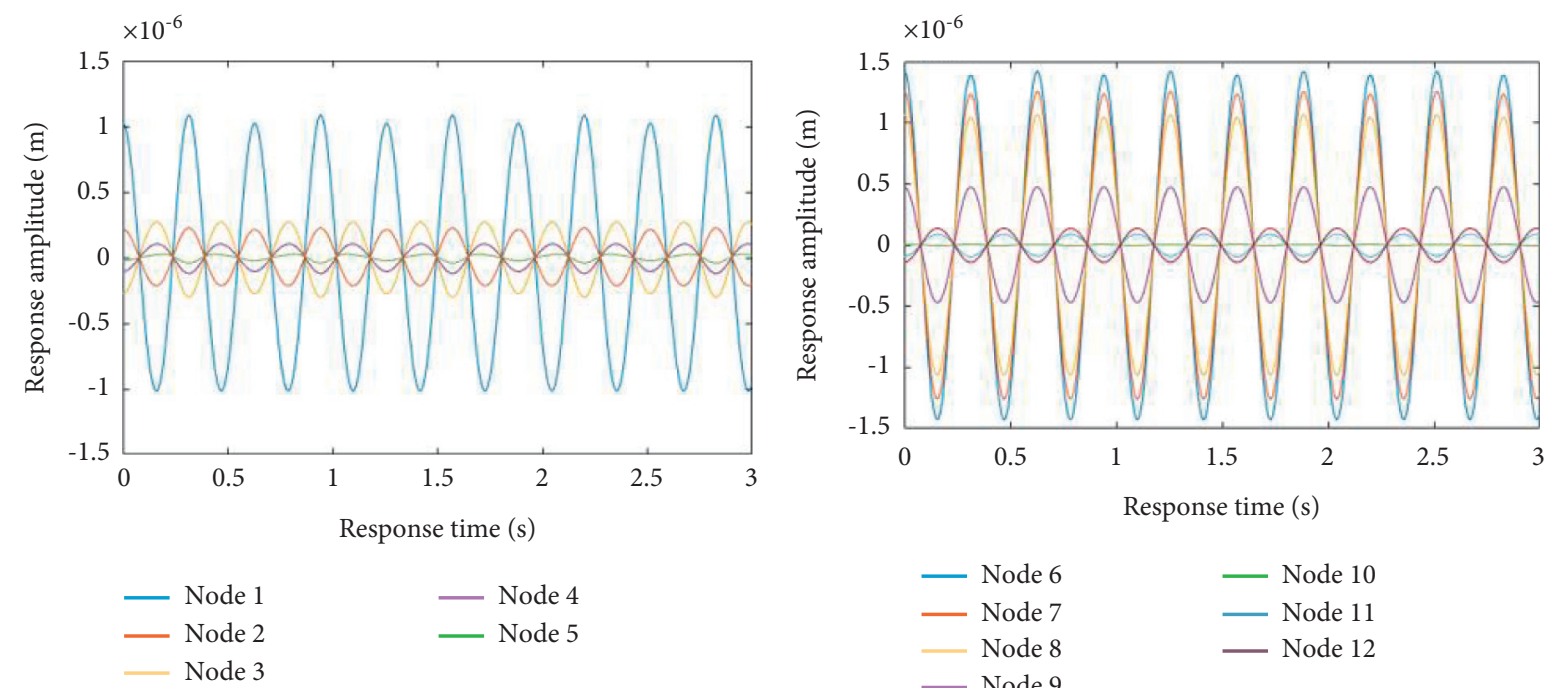

(a)

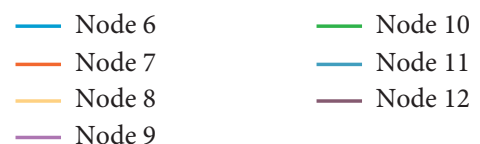

(b)

Figure 23: Continued. 

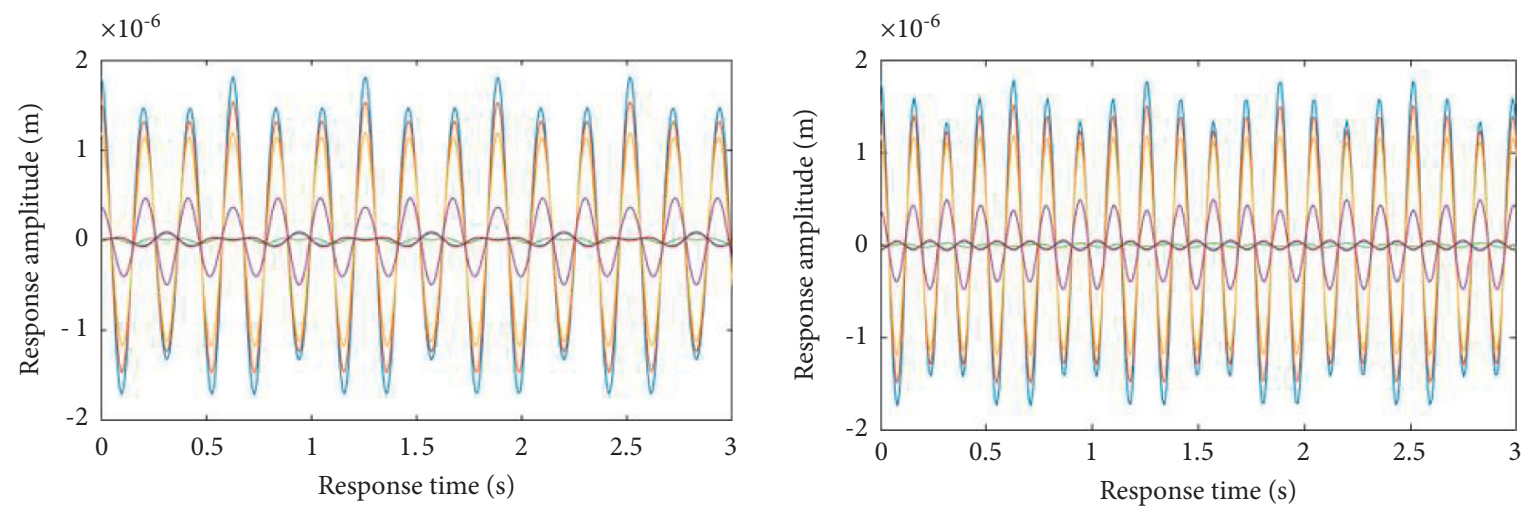

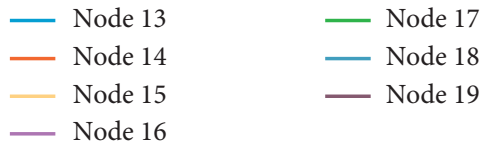

(c)

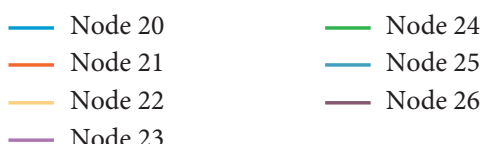

(d)

Figure 23: Time-domain response of parallel system under bilateral transmission. (a) Motor shaft. (b) Threshing cylinder I. (c) Threshing cylinder II. (d) Threshing cylinder III.

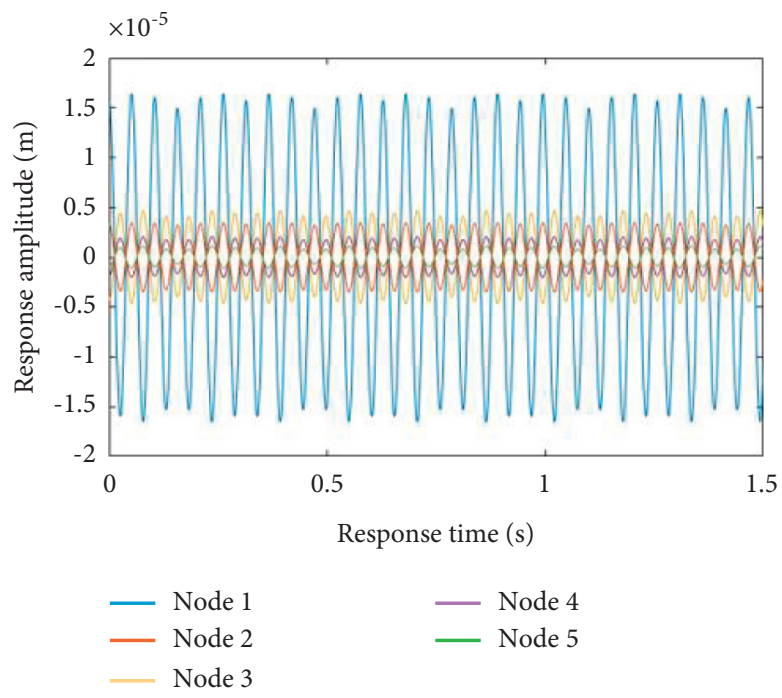

(a)

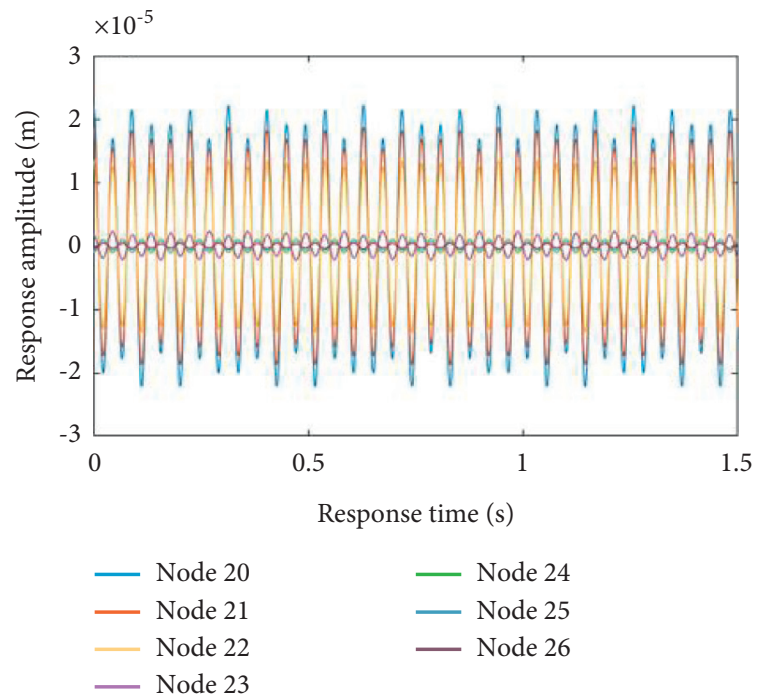

(b)

FIgURE 24: Time-domain response at high speed. (a) The motor shaft. (b) Threshing cylinder III.

TABLE 2: Vibration amplitude of left end bearing seat in unilateral transmission $\left(\mathrm{m} / \mathrm{s}^{2}\right)$.

\begin{tabular}{lcccccccccc}
\hline \multirow{2}{*}{ Rotating speed (r/min) } & \multicolumn{9}{c}{ Amplitude at different positions in the axial direction $\left(\mathrm{m} / \mathrm{s}^{2}\right)$} \\
& 1 & 2 & 3 & 4 & 5 & 6 & 7 & 8 & 9 \\
\hline 550 & 0.109 & 0.12 & 0.104 & 0.102 & 0.094 & 0.084 & 0.072 & 0.072 & 0.063 & 0.060 \\
600 & 0.187 & 0.178 & 0.164 & 0.148 & 0.14 & 0.127 & 0.115 & 0.104 & 0.086 & 0.078 \\
650 & 0.19 & 0.183 & 0.178 & 0.179 & 0.151 & 0.131 & 0.128 & 0.126 & 0.102 & 0.107 \\
700 & 0.321 & 0.233 & 0.212 & 0.197 & 0.271 & 0.246 & 0.228 & 0.200 & 0.169 & 0.16 \\
750 & 0.460 & 0.47 & 0.381 & 0.328 & 0.38 & 0.319 & 0.305 & 0.273 & 0.219 & 0.228 \\
800 & 0.518 & 0.513 & 0.416 & 0.543 & 0.5 & 0.338 & 0.336 & 0.272 & 0.263 & 0.251 \\
\hline
\end{tabular}


TABLE 3: Vibration amplitude of bearing seat at right end in unilateral transmission $\left(\mathrm{m} / \mathrm{s}^{2}\right)$.

\begin{tabular}{lccccccccccc}
\hline \multirow{2}{*}{ Rotating speed (r/min) } & \multicolumn{9}{c}{ Amplitude at different positions in the axial direction $\left(\mathrm{m} / \mathrm{s}^{2}\right)$} \\
& 1 & 2 & 3 & 4 & 5 & 6 & 7 & 8 & 9 & 10 \\
\hline 550 & 0.044 & 0.065 & 0.063 & 0.075 & 0.083 & 0.099 & 0.098 & 0.119 & 0.13 & 0.135 \\
600 & 0.078 & 0.092 & 0.103 & 0.096 & 0.126 & 0.148 & 0.163 & 0.176 & 0.176 & 0.201 \\
650 & 0.079 & 0.107 & 0.101 & 0.134 & 0.138 & 0.154 & 0.229 & 0.207 & 0.209 & 0.247 \\
700 & 0.136 & 0.124 & 0.135 & 0.225 & 0.247 & 0.29 & 0.319 & 0.33 & 0.344 & 0.371 \\
750 & 0.203 & 0.256 & 0.244 & 0.249 & 0.351 & 0.382 & 0.429 & 0.455 & 0.449 & 0.525 \\
800 & 0.235 & 0.341 & 0.273 & 0.419 & 0.464 & 0.465 & 0.469 & 0.454 & 0.53 & 0.568 \\
\hline
\end{tabular}

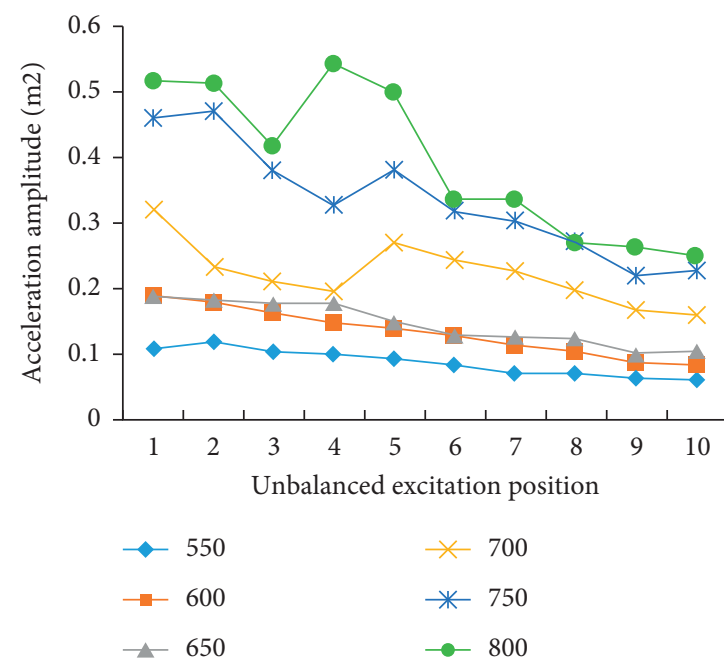

FIgURE 25: The vibration amplitude change of the left end bearing seat.

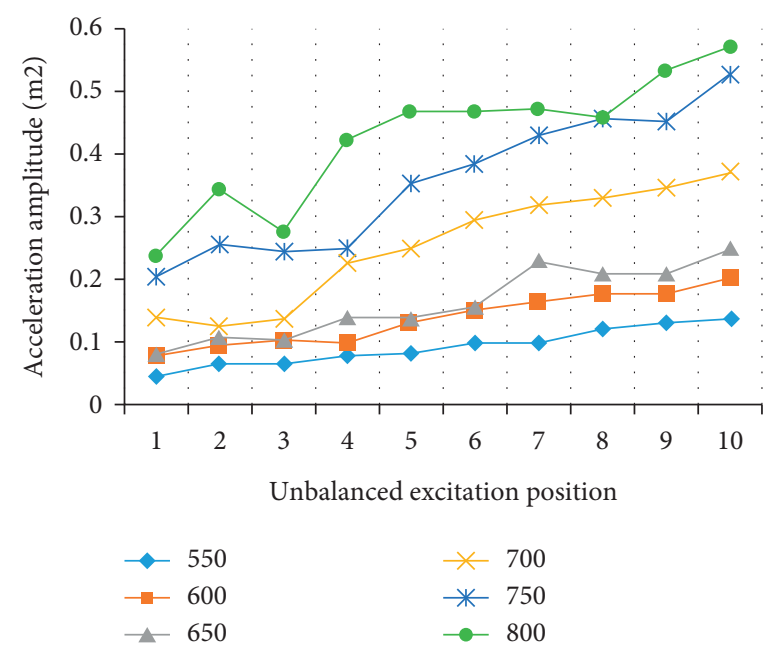

FIgURE 26: The vibration amplitude change of the right end bearing seat.

Under other conditions unchanged, change the transmission mode of the multidrum parallel system to bilateral transmission. The vibration response amplitude of the system is shown in Table 4 and Table 5.

Vibration amplitude change curve of the bearing seat at both ends of the drum II is shown in Figure 29 and Figure 30.
In addition, the unbalanced excitation is applied at position 5, and the vibration amplitudes of the shaft end for unilateral transmission and bilateral transmission are shown in Table 6.

As shown in Table 6, it can be seen from the amplitude data that, with the increase of speed, the range of vibration 


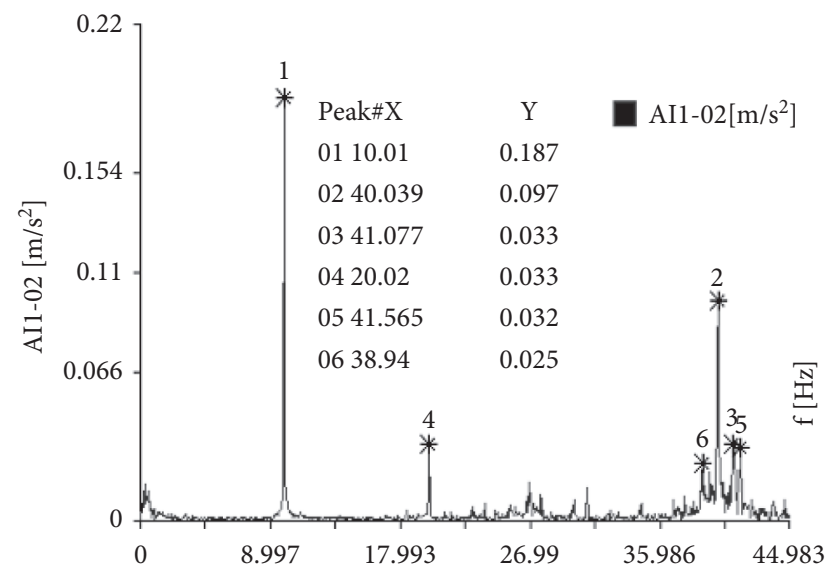

FIgURE 27: Spectrum diagram when weight is applied at No. 1 position.

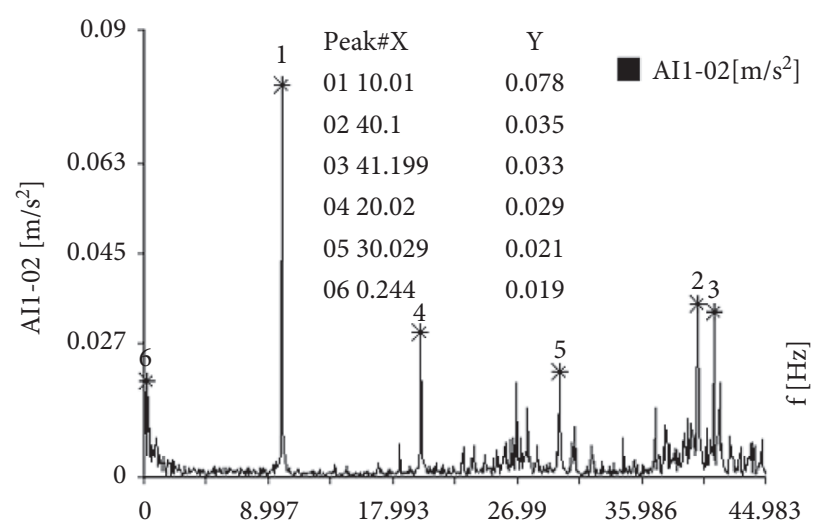

FIGURE 28: Spectrogram when weight is applied at No. 10 position.

TABLE 4: Vibration amplitude at the left end bearing seat during bilateral transmission $\left(\mathrm{m} / \mathrm{s}^{2}\right)$.

\begin{tabular}{lcccccccccc}
\hline \multirow{2}{*}{ Rotating speed (r/min) } & \multicolumn{9}{c}{ Amplitude at different positions in the axial direction $\left(\mathrm{m} / \mathrm{s}^{2}\right)$} \\
& 1 & 2 & 3 & 4 & 5 & 6 & 7 & 8 & 9 \\
\hline 550 & 0.095 & 0.089 & 0.114 & 0.108 & 0.084 & 0.08 & 0.065 & 0.071 & 0.062 & 0.052 \\
600 & 0.188 & 0.175 & 0.157 & 0.136 & 0.144 & 0.125 & 0.105 & 0.103 & 0.093 & 0.066 \\
650 & 0.181 & 0.176 & 0.165 & 0.153 & 0.159 & 0.139 & 0.136 & 0.137 & 0.117 & 0.110 \\
700 & 0.351 & 0.335 & 0.319 & 0.289 & 0.268 & 0.241 & 0.19 & 0.187 & 0.184 & 0.163 \\
750 & 0.377 & 0.432 & 0.428 & 0.414 & 0.384 & 0.253 & 0.227 & 0.21 & 0.254 & 0.183 \\
800 & 0.512 & 0.497 & 0.489 & 0.478 & 0.470 & 0.426 & 0.37 & 0.358 & 0.241 & 0.223 \\
\hline
\end{tabular}

TABLE 5: Vibration amplitude at the bearing seat at the right end during bilateral transmission $\left(\mathrm{m} / \mathrm{s}^{2}\right)$.

\begin{tabular}{lccccccccccc}
\hline \multirow{2}{*}{ Rotating speed (r/min) } & \multicolumn{9}{c}{ Amplitude at different positions in the axial direction $\left(\mathrm{m} / \mathrm{s}^{2}\right)$} \\
& 1 & 2 & 3 & 4 & 5 & 6 & 7 & 8 & 9 \\
\hline 550 & 0.037 & 0.045 & 0.067 & 0.077 & 0.071 & 0.093 & 0.098 & 0.117 & 0.120 & 0.124 \\
600 & 0.079 & 0.089 & 0.095 & 0.098 & 0.126 & 0.148 & 0.148 & 0.172 & 0.183 & 0.191 \\
650 & 0.078 & 0.107 & 0.134 & 0.135 & 0.139 & 0.15 & 0.19 & 0.226 & 0.206 & 0.25 \\
700 & 0.153 & 0.174 & 0.2 & 0.213 & 0.236 & 0.286 & 0.264 & 0.341 & 0.359 & 0.378 \\
750 & 0.170 & 0.231 & 0.278 & 0.31 & 0.343 & 0.356 & 0.378 & 0.447 & 0.499 & 0.523 \\
800 & 0.238 & 0.331 & 0.337 & 0.362 & 0.428 & 0.514 & 0.517 & 0.593 & 0.603 & 0.617 \\
\hline
\end{tabular}




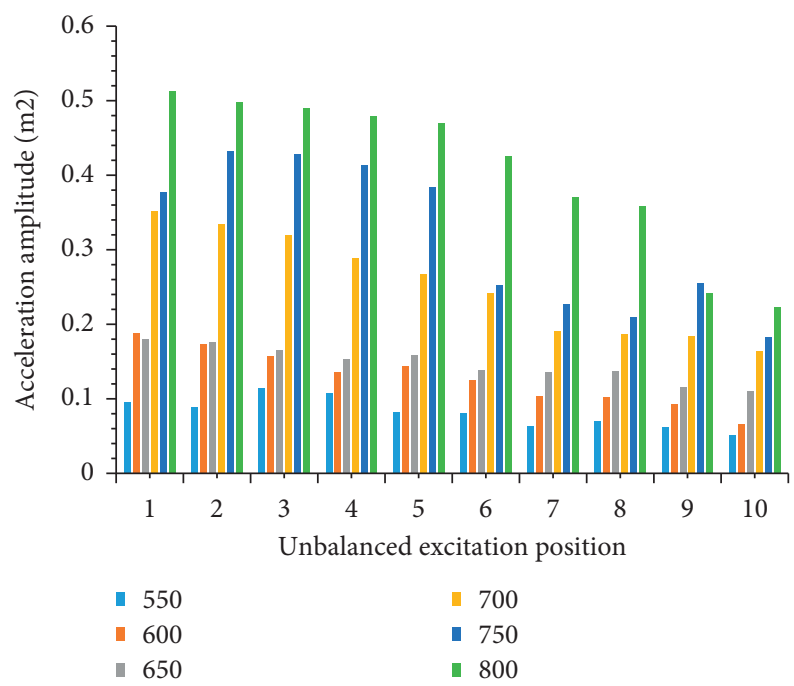

Figure 29: Vibration amplitude change of the left end bearing seat.

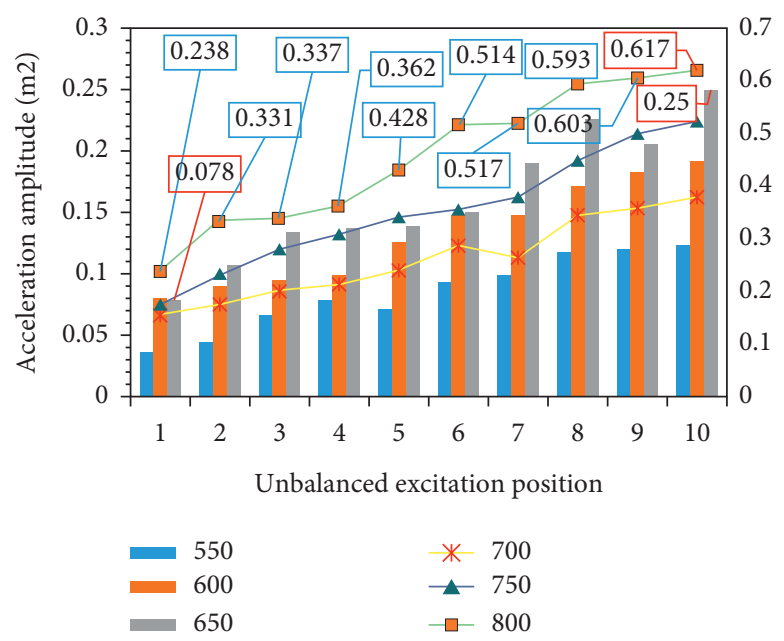

FIGURE 30: Vibration amplitude change of the right end bearing seat.

TABLE 6: Vibration response under the same unbalanced excitation under different transmission modes.

\begin{tabular}{lccccccc}
\hline & & 550 & 600 & 650 & 700 & 750 & 800 \\
\hline \multirow{2}{*}{ Unilateral transmission } & Left end & 0.094 & 0.140 & 0.151 & 0.271 & 0.380 & 0.500 \\
& Right end & 0.083 & 0.126 & 0.138 & 0.247 & 0.351 & 0.464 \\
Double-sided transmission & Left end & 0.084 & 0.144 & 0.159 & 0.268 & 0.384 & 0.470 \\
& Right end & 0.071 & 0.126 & 0.139 & 0.236 & 0.343 & 0.428 \\
\hline
\end{tabular}

amplitude under bilateral transmission is smaller than that under unilateral transmission. That is, under bilateral transmission, the system is more stable.

By comparing the results of the unbalanced response amplitude of the system with the change of the counterweight position under various working conditions, it can be seen that even if the symmetrical position on the threshing drum is used as the excitation point, the unbalance is produced at the same position where a certain difference in the balance response is. There may be two reasons for this phenomenon: the measured roller itself has a certain imbalance. This will be superimposed with the imbalance applied, resulting in a certain difference in the imbalance response generated at the symmetrical position. In addition, 
due to the polygon effect in the working process of the transmission chain, the tight side of the chain is always in a stretched state. To a certain extent, it can be considered that the chain transmission system has a certain influence on the boundary conditions of the threshing drum.

\section{Conclusion}

(1) It can be seen from the vibration shape response results of unilateral transmission and bilateral transmission that the response amplitude of each rotating body in the system under unilateral transmission is $2 \times 10^{-6} \mathrm{~m} \sim 2.5 \times 10^{-6} \mathrm{~m}$. In addition, from the time-domain diagram of vibration, the vibration shape changes of each node during bilateral transmission are also more stable. It can be seen that the change in the transmission mode makes the system more stable.

(2) The existence of the transmission chain makes the various rollers in the system influence each other. It has an impact on the coupling of the entire system in the vertical direction and the mode shape in this direction. The change of the transmission mode also makes a big change in the vibration transmission path in the system, resulting in a change in the unbalanced response characteristics of each unit in the system.

(3) Through the comparison of experiment and numerical simulation, it can be found that the results of the two are consistent, which can verify the validity of the model. Based on this model, the vibration characteristics of the threshing system can be studied more deeply, and the theoretical basis for vibration reduction design can be provided.

\section{Data Availability}

The data used to support the findings of this study are available from the corresponding author upon request.

\section{Conflicts of Interest}

The authors declare that they have no conflicts of interest.

\section{Acknowledgments}

This research work was supported by the Single Technology Research and Development Project of Jiangsu Agricultural Science and Technology Independent Innovation Fund (CX(21)3144), National Natural Science Foundation of China (52175235), the National Key Research and Development Project (2017YFD0700203), and Jiangsu Province “Six Talents Peak" High-level Talent Project (GDZB-085).

\section{References}

[1] Z. Tang, Y. Li, X. Li, and T. Xu, "Structural damage modes for rice stalks undergoing threshing," Biosystems Engineering, vol. 186, pp. 323-336, 2019.
[2] Z. Tang, M. L. Wang, H. T. Zhang, Y. P. Zhou, and Y. Li, "Variation and modal characteristic of tangential threshing cylinder undergoing threshing dynamics," Mathematical Problems in Engineering, vol. 2020, Article ID 1723893, 15 pages, 2020.

[3] Z. Tang, X. Li, X. Liu, H. Ren, and B. Zhang, "Dynamic balance method for grading the chain drive double threshing drum of a combine harvester," Applied Sciences, vol. 10, no. 3, pp. 1026-1046, 2020.

[4] Z. Tang, H. T. Zhang, and Y. P. Zhou, "Unbalanced vibration identification of tangential threshing cylinder induced by rice threshing process," Shock and Vibration, vol. 2018, Article ID 4708730, 14 pages, 2018.

[5] W. Wang, Q. Li, J. Gao, J. Yao, and P. Allaire, "An identification method for damping ratio in rotor systems," "Mechanical Systems and Signal Processing, vol. 68-69, pp. 536-554, 2016.

[6] H. Quan, J. Cheng, and G. Y. Peng, "Effect of screw centrifugal inducer on mechanical characteristics of vortex pump," Journal of Drainage and Irrigation Machinery Engineering, vol. 39, no. 4, pp. 345-350, 2021.

[7] Z. W. Mu, X. W. Gui, Q. C. Xia, and Z. S. Zhang, "Structural optimization design of impeller vane of shaft seal pump based on CFD," Journal of Drainage and Irrigation Machinery Engineering, vol. 1, pp. 1-7, 2021.

[8] Y. Liu, Y. L. Zhao, J. T. Li, H. Ma, Q. Yang, and X. X. Yan, "Application of weighted contribution rate of nonlinear output frequency response functions to rotor rub-impact," Mechanical Systems and Signal Processing, vol. 136, Article ID 106518, 2020.

[9] X. Ge, Z. Luo, Y. Ma, H. Liu, and Y. Zhu, "A novel data-driven model based parameter estimation of nonlinear systems," Journal of Sound and Vibration, vol. 453, pp. 188-200, 2019.

[10] K. Wu, Z. Liu, Q. Ding, P. Shackleton, and A. D. Ball, "Vibration responses of rotor systems in diesel multiple units under dynamic spatial misalignments and base motions," Journal of Sound and Vibration, vol. 492, Article ID 115817, 2021.

[11] S. Zhao, X. Ren, W. Deng, K. Lu, and C. Fu, “A transient characteristic-based balancing method of rotor system without trail weights," Mechanical Systems and Signal Processing, vol. 148, Article ID 107117, 2021.

[12] T. F. Oliver, H. H. Morten, and Y. Anders, "A novel methodology for analyzing modal dynamics of multi-rotor wind turbines," Journal of Sound and Vibration, vol. 493, Article ID 115810, 2021.

[13] H. Roy, S. Chandraker, J. K. Dutt, and T. Roy, "Dynamics of multilayer, multidisc viscoelastic rotor - an operator based higher order classical model," Journal of Sound and Vibration, vol. 369, pp. 87-108, 2016.

[14] A. Mereles and K. L. Cavalca, "Modeling of multi-stepped rotor-bearing systems by the continuous segment method," Applied Mathematical Modelling, vol. 96, pp. 402-430, 2021.

[15] S. Wang, R. Zhu, and J. Feng, "Study on load sharing behavior of coupling gear-rotor-bearing system of gtf aero-engine based on multi-support of rotors," Mechanism and Machine Theory, vol. 147, Article ID 103764, 2020.

[16] R. Dupont, "Robust rotor dynamics for high-speed air bearing spindles," Precision Engineering, vol. 40, pp. 7-13, 2015.

[17] H. T. Zhang, Z. Tang, Y. Li, X. Liu, and H. Ren, "Lightweight threshing rack under multisource excitation based on modal optimization method," Advances in Materials Science and Engineering, vol. 2020, Article ID 2029501, 17 pages, 2020. 
[18] Z. Y. Lu, S. Zhong, H. Z. Chen, X. D. Wang, J. J. Han, and C. Wang, "Nonlinear response analysis for a dual-rotor system supported by ball bearing," International Journal of Non-linear Mechanics, vol. 128, Article ID 103627, 2021.

[19] P. Novotný, J. Hrabovský, and J. Juračka, "Effective thrust bearing model for simulations of transient rotor dynamics," International Journal of Mechanical Sciences, vol. 157, pp. 374-383, 2019.

[20] Y. Li, Z. Luo, J. Liu, H. Ma, and D. Yang, "Dynamic modeling and stability analysis of a rotor-bearing system with bolteddisk joint," Mechanical Systems and Signal Processing, vol. 158, no. 24, Article ID 107778, 2021.

[21] P. Yu, L. Li, G. Chen, and M. Yang, "Dynamic modelling and vibration characteristics analysis for the bolted joint with spigot in the rotor system," Applied Mathematical Modelling, vol. 94, pp. 306-331, 2021.

[22] E. Chipato, A. D. Shaw, and M. I. Friswell, "Frictional effects on the nonlinear dynamics of an overhung rotor," Communications in Nonlinear Science and Numerical Simulation, vol. 78, Article ID 104875, 2021.

[23] D. Shin and A. Palazzolo, "Nonlinear analysis of a geared rotor system supported by fluid film journal bearings," Journal of Sound and Vibration, vol. 475, Article ID 115269, 2020.

[24] F. K. Choy, Y. K. Tu, J. J. Zakrajsek, and D. P. Townsend, "Effects of gear box vibration and mass imbalance on the dynamics of multistage gear transmission," Journal of Vibration and Acoustics, vol. 113, no. 3, pp. 333-344, 1991.

[25] F. K. Choy, "Modal simulation of gear box vibration with experimental correlation," Journal of Mechanical Transmission, vol. 42, no. 1, pp. 143-149, 2018.

[26] J. Taghipour, M. Dardel, and M. H. Pashaei, "Nonlinear vibration mitigation of a flexible rotor shaft carrying a longitudinally dispositioned unbalanced rigid disc," Nonlinear Dynamics, vol. 104, no. 3, pp. 2145-2184, 2021.

[27] A. Tatar, C. W. Schwingshackl, and M. I. Friswell, "Dynamic behaviour of three-dimensional planetary geared rotor systems," Mechanism and Machine Theory, vol. 134, pp. 39-56, 2019.

[28] Z. Taherkhani and H. Ahmadian, "Stochastic model updating of rotor support parameters using bayesian approach," Mechanical Systems and Signal Processing, vol. 158, no. 7, Article ID 107702, 2021.

[29] Y. Cao, H. Yao, Q. Li, P. Yang, and B. Wen, "Vibration mitigation and dynamics of a rotor-blade system with an attached nonlinear energy sink," International Journal of Nonlinear Mechanics, vol. 127, Article ID 103614, 2020. 